NBER WORKING PAPER SERIES

\title{
ROBUST DECARBONIZATION OF THE US POWER SECTOR: POLICY OPTIONS
}

\author{
James H. Stock \\ Daniel N. Stuart \\ Working Paper 28677 \\ http://www.nber.org/papers/w28677
NATIONAL BUREAU OF ECONOMIC RESEARCH
1050 Massachusetts Avenue
Cambridge, MA 02138 \\ April 2021
}

We thank Matt Kotchen for helpful comments. The views expressed herein are those of the authors and do not necessarily reflect the views of the National Bureau of Economic Research. Stuart acknowledges funding from the NSF Graduate Research Fellowship and National Wildlife Federation.

NBER working papers are circulated for discussion and comment purposes. They have not been peer-reviewed or been subject to the review by the NBER Board of Directors that accompanies official NBER publications.

(C) 2021 by James H. Stock and Daniel N. Stuart. All rights reserved. Short sections of text, not to exceed two paragraphs, may be quoted without explicit permission provided that full credit, including (c) notice, is given to the source. 
Robust Decarbonization of the US Power Sector: Policy Options

James H. Stock and Daniel N. Stuart

NBER Working Paper No. 28677

April 2021

JEL No. H23,Q48,Q54,Q58

\begin{abstract}
$\underline{\text { ABSTRACT }}$
To reliably achieve deep decarbonization of the US power sector, a candidate policy must perform robustly across a range of possible future trajectories of demand, fossil fuel prices, and prices of new wind and solar capacity. Using a modified version of the NREL ReEDS model with scenarios that span different trajectories of demand, fuel prices, and technology costs, we find that some recently proposed policies can robustly achieve $80 \%$ decarbonization (relative to 2005 emissions) or more by 2035 , but many do not. The two robustly successful policies are a tradeable performance standard (TPS) and a hybrid Clean Electricity Standard (CES) with a $100 \%$ clean target, partial crediting of gas generation, and a $\$ 40 / \mathrm{mton} \mathrm{CO} 2$ alternative compliance payment (ACP) backstop. Both are nearly as cost effective as the emissionsequivalent efficient policy. A $\$ 40$ carbon tax nearly achieves the robust $80 \%$ threshold and, in most scenarios, drives deep decarbonization. A 90\% CES (without partial crediting) fails to achieve robust 2035 decarbonization because it need not drive coal out of the system. Simply extending renewable energy tax credits, which are set to expire, does not drive significant decarbonization in most scenarios, nor does relying on increased ambition in green-leaning states.
\end{abstract}

James H. Stock

Department of Economics

Harvard University

Littauer Center M26

Cambridge, MA 02138

and NBER

James_Stock@harvard.edu

Daniel N. Stuart

Harvard University

dstuart1@g.harvard.edu 


\section{Introduction}

A key step towards decarbonizing the US economy is decarbonizing the power sector. Proposals for how to do so range from an economy-wide carbon tax to sectoral standards to simply relying on falling renewables prices without significant policy changes. While there is urgency, there is also considerable uncertainty about the economic and technological environment in which any policy will operate. Thus, to achieve rapid deep decarbonization, a proposed policy must be robust to alternative trajectories of total electricity demand and the prices of fossil fuels and green technologies.

This paper uses a detailed power sector simulation model, a modification of the National Renewable Energy Laboratory's Regional Energy Deployment System (ReEDS) model, to evaluate ten policies for cutting carbon dioxide emissions in the power sector. For each policy, we estimate its emissions path and cost under ten economic scenarios that cover baseline (low) and high electricity demand, low and high renewable technology prices, and low and high natural gas prices.

We evaluate each policy using three criteria. Decarbonization target dates have become a widelyadopted policy framework internationally, and the Biden administration has set a goal of deep decarbonization of the power sector by 2035. That target, like other targets, does not provide loopholes if, say, technology and energy prices are unfavorable. Our first criterion, then, is whether a candidate policy achieves robust decarbonization by 2035, which we define as reducing carbon emissions in every demand/price scenario by at least $80 \%$ by 2035 , relative to 2005. Second, we estimate the cost effectiveness of a policy by comparing it to an emissionsequivalent efficient policy (cap-and-trade). Third, we conduct a limited cost-benefit test by comparing the policy's average abatement cost over 2022-2035 to the Social Cost of Carbon (SCC), although we caution that this comparison likely understates the benefit-cost ratio because we do not incorporate health co-benefits and because it ignores longer-term dynamic effects of the policy on technology prices.

The policies we consider are versions of policies under current discussion. Four of the policies are sectoral standards: a 90\% Clean Electricity Standard (CES), two hybrid CESs that include partial crediting for natural gas and an alternative compliance payment (ACP) backstop as in the CLEAN Futures Act, and a Tradable Performance Standard (TPS) that is an idealized version of aggressive rate-based regulation under the Clean Air Act, although the TPS could also be implemented legislatively. Two of the policies are carbon taxes, at $\$ 40$ and $\$ 20$ per ton of carbon dioxide $\left(\mathrm{CO}_{2}\right)$ increasing 3\% per year. We consider an extension of the renewables production and investment tax credits (PTC/ITC) through 2036 (President Biden's American Jobs Plan proposes an expansion and ten-year extension of renewables tax credits). The American Jobs Plan also proposes combining the tax credit extension with a CES, so we consider a hybrid CES 
combined with the tax credit extension. Finally, in the absence of strong federal policy, some states could pursue more aggressive action on their own, so we consider state ambition in which 14 green states adopt a CES with a $100 \%$ non-emitting requirement in 2035 , both with and without the support of the federal tax credit extension. Details are provided in Section 4.

Our main finding is that only two of the individual policies result in 2035 robust decarbonization: the hybrid clean energy standard with a 100\% clean requirement in 2035 with partial crediting for natural gas and an ACP of \$40/MWh, and the TPS. Both policies have the effect of explicitly or implicitly targeting emissions. Both policies are cost-effective, with average abatement costs ( $\$$ per ton $\mathrm{CO}_{2}$ abated) no more than $10 \%$ greater than the efficient capand-trade policy in nine of the ten scenarios. In addition, both policies pass a climate-only costbenefit test using the current US Government Social Cost of Carbon, with cost per ton abated ranging across scenarios from $\$ 10$ - \$34 for the hybrid 100\% CES and \$15 - \$32 for the TPS. Under both policies, national average electricity prices, averaged over 2022-2036, are modestly higher than under the no-policy scenario, by $\$ 1-\$ 4 / \mathrm{MWh}$.

The $\$ 40$ carbon tax achieves deep decarbonization in most scenarios, although it yields emissions reductions of only $78 \%-79 \%$ by 2035 when the price of renewables is high and natural gas prices are low because gas generation remains attractive even with the tax. Arguably these reductions are within modeling error of the $80 \%$ threshold, so the $\$ 40$ carbon tax can be generously interpreted as also achieving 2035 robust decarbonization.

The other policies fail to achieve 2035 robust decarbonization because they succeed in some but not all scenarios. The $90 \%$ CES without partial crediting and no alternative compliance mechanism reliably achieve $90 \%$ non-fossil generation, however because it does not discriminate between coal and natural gas, it achieves only 74\%-76\% emissions reduction when natural gas prices are high and demand is high, because coal is then economic and remains in the system.

We estimate that the tax credit extension alone does not come close to achieving 2035 robust decarbonization; rather, the effectiveness of the tax credits depends heavily on the economic environment. In the most favorable case - low renewables cost and high natural gas prices - the no-policy case achieves $64 \%-71 \%$ emissions reduction by 2035 , and extending the tax credits increases this to a $87 \%$ reduction. But with less favorable technology and price projections, extending the tax credits results in only modest decarbonization, with 2035 emissions reductions as little as $43 \%$. In addition, simply relying on state ambition, with or without the tax credit extension, fails to produce much additional emissions reduction because of cross-state leakage.

We also consider a combination of the tax credits and the hybrid 100\% CES with \$40 ACP. Adding the tax credit extension to the hybrid CES has three main effects. First, the tax credits serve as insurance for the hybrid CES, in particular in the cases in which the hybrid CES has the 
smallest reductions - when the price of renewables is high - the tax credits provide substantial additional abatement. As a result, this combined policy achieves 91\%-95\% abatement across all ten scenarios. Second, the tax credit extension shifts the cost of decarbonization from the ratepayer to the taxpayer: augmenting the hybrid CES with the extension reduces average electricity prices, not just compared to the hybrid CES without the extension but compared to BAU. Whether shifting costs from the ratepayer to the taxpayer is progressive depends on how the additional fiscal burden is financed. Third, augmenting the hybrid CES with the tax credit extension is estimated to cost the federal government $\$ 10 \mathrm{~B}-\$ 29 \mathrm{~B}$ annually over the life of the extension, depending on the scenario. The tax credit is both least effective, in terms of emissions reductions, and has the highest fiscal burden, when the price of renewables is low, since that is when the most new renewables would be built under the hybrid CES without the extension. In general, the combined policy is not cost-effective compared to the emissions-equivalent efficient policy, especially when renewables prices are low so the tax credit is almost entirely an inframarginal transfer.

\section{Previous Literature}

This paper contributes to the large body of work that uses power sector simulation models to study power sector policy. Relative to this literature, our main contribution is to examine a large number of alternative policy instruments (no-policy business-as-usual and 10 policy cases) across five alternative technology cost scenarios and two alternative electrification scenarios; to include among these a hybrid CES with an ACP backstop; and to undertake these comparisons using a consistent set of updated cost and demand projections from the Energy Information Administration and NREL. Using updated cost and demand projections is critical to reflect recent changes in the power system including the recent decline in coal generation, planned and economic coal plant retirements, recent and projected declines in the prices of renewables, and updated projections of technology costs including costs of grid-scale battery storage.

Although some of the policies we consider, including a carbon tax and a CES have been studied extensively, there are fewer studies of extensions of renewable tax credits and enhanced state ambition, and we are not aware of publicly available studies of the CLEAN Future Act hybrid CES with alternative compliance payment backstop. We calibrate the policies that involve national carbon pricing to achieve approximately $90 \%$ decarbonization of the power sector, relative to 2005 .

The studies closest to ours are Phadke et al. (2020) (the "Goldman 2035 Report") and Larsen et al. (2020, 2021). Phadke et al. (2020) also uses the ReEDS model to estimate system costs and emissions under two policies, a 90\% CES (no partial crediting and no ACP) and \$40 carbon tax rising at $1.5 \%$ real. Under the $90 \%$ CES, Phadke et al. (2020) exogenously retire coal capacity linearly until there is no coal generation in 2035. Because natural gas is the only economic 
substitute for coal generation in the ReEDS model, this implies mechanically that $10 \%$ of generation is from natural gas in 2035 under all technology price and demand scenarios. ${ }^{1}$ In contrast, we use the ReEDS model to determine coal retirement endogenously depending on economic conditions. As a result, 2035 emissions under the $90 \%$ CES vary across price scenarios. In our simulations, when gas prices are low, nearly all coal plants are retired so estimated emissions are only slightly greater than those in Phadke et al. (2020), however when gas prices are high, some coal plants remain economical in ReEDS leading to the $10 \%$ of nonclean generation in 2035 being coal-heavy. Additionally, we analyze 9 additional policies including a hybrid CES with an ACP backstop and analyze the cost-effectiveness of each policy relative to an efficient cap-and-trade system. Larsen et al. (2020) use a modified version of the EIA National Energy Modeling System (NEMS) to estimate the effect of two economy-wide carbon taxes on emissions, augmented by complementary policies, not including a PTC/ITC extension. Larsen et al. (2021) use their modified NEMS model to estimate the effect of the GREEN Act, which includes an extension of the renewables PTC/ITC and other tax credits, however they do not model the tax credit extension in conjunction with sectoral standards. Our results for the tax credit extension are broadly comparable to theirs, although the range of our emissions reductions is wider.

Other related studies using similar power sector models include the Energy Information Administration's Annual Energy Outlook $(2017,2019)$ (EIA NEMS model), the Stanford Energy Modeling Forum (EMF 32) as summarized in Fawcett et al. (2018) and Bistline, Creason and Murray (2018) (16 different models including ReEDS), Gillingham, Ovaere, and Weber (2021) and Gillingham and Huang (2019) (both use a modified version of NEMS), Phadke et al. (2020) (ReEDS), and Larsen et al. (2020) (a modified version of NEMS). A separate line of research focuses on general equilibrium effects of carbon policies, including through the tax code; see Goulder, Hafstead and Williams (2016) and Goulder and Hafstead (2018).

\section{Simulation Model}

\subsection{Overview}

This paper uses a modified version of the National Renewable Energy Laboratory's Regional Energy Deployment System (ReEDS) capacity expansion model. ${ }^{2}$ ReEDS is a quantitative equilibrium model of the power sector. ReEDS solves the problem of minimizing aggregate system costs while meeting load in every region and time period in the continental United States. ${ }^{3}$ This can be viewed as the social planner's problem of supplying power at least-cost.

\footnotetext{
${ }^{1}$ See Figure 8 of the Appendix in Phadke et al. (2020).

${ }^{2}$ There is detailed documentation available for the ReEDS model: https://www.nrel.gov/docs/fy20osti/74111.pdf. For a list of publications using the ReEDS model, see https://www.nrel.gov/analysis/reeds/publications.html.

${ }^{3}$ ReEDS is a mixed integer linear optimization program solved numerically using the CPLEX optimizer.
} 
Thus, the solution to ReEDS can be viewed as the equilibrium allocation under perfect information and perfect competition. Following standard practice for ReEDS (e.g., NREL Standard Scenario Report, 2020; Phadke et al. 2020), we solve the model using myopic expectations, in which current-period prices and policies are assumed to extend into the future. The Appendix provides a comparison of results under myopic expectations and perfect foresight.

We modify ReEDS to incorporate novel policy scenarios. We refer to this modified model as mReEDS when it is necessary to distinguish our modifications from the base NREL ReEDS model. All simulations are for the period 2022-2038, with the model solved at four-year steps.

\subsection{Supply and demand}

The supply side of ReEDS determines capacity investment and generation for 134 distinct regions in the United States at 17 yearly time-slices for the time period 2010-2038. ${ }^{4}$ The 17 annual time slices reflect four blocks for each season along with a summer peak load period. To parameterize the model, ReEDS uses cost and performance parameters from NREL's Annual Technology Baseline (ATB). We use the 2020 version of the ATB.

The ATB includes capital cost, fixed operating costs, and variable operating costs for renewable and storage technologies including land-based wind, offshore wind, utility photovoltaic, concentrated solar power, geothermal, and battery storage. Cost parameters for all other technologies come from EIA's 2020 Annual Energy Outlook. The ATB also provides detailed resource estimates for each renewable technology. Distinct production profiles are modeled for separate resource bins for each technology, where each bin measures the characteristics of a given resource. ${ }^{5}$

ReEDS accounts for system reliability to ensure that electricity load is met in every time period while maintaining resource adequacy and operational reliability. Resource adequacy is met by adding NERC planning reserve requirements as constraints to the objective function. In practice, this means the system must have sufficient "firm" capacity to meet forecasted peak demand plus a reserve margin. Variable renewable electricity (VRE) technologies receive only partial capacity credit for purposes of meeting the reserve margin. Because the marginal capacity value of new VRE is a function of the existing VRE stock, ReEDS uses an 8,760-hour load profile to track load and VRE generation. This procedure ensures that the capacity credit calculation reflects both the timing of peak load and the hourly generation profile of each renewable technology.

\footnotetext{
${ }^{4}$ This discussion of the ReEDS model relies on the 2019 documentation available here: https://www.nrel.gov/docs/fy20osti/74111.pdf

${ }^{5}$ Each specific renewable resource is characterized by the range of potential output, the potential installed capacity, and the average capacity factor.
} 
Operational reliability is modeled as ancillary reserve requirements including spinning, regulation, and flexibility reserves. ReEDS includes technology-specific ramp rates and the ramping requirements of a specific reserve product to reflect the different abilities of different generating technologies to provide reserve products.

Curtailment is calculated as a statistical estimate of expected excessive generation given load, VRE output and minimum generation levels for thermal units in a given location and timeperiod.

Storage technologies are modeled as arbitrage technologies that shift load, provide planning and operating reserves, and reduce the curtailment of variable renewable energy (VRE). Load shifting refers to intraday charging during low demand and discharging during peak demand periods. The model includes 2, 4, 6, 8, and 10-hour battery storage durations.

Technology-specific regional cost multipliers are applied to reflect variations in installation costs across the United States, which come from EIA cost estimates for particular cities. Regional cost multipliers are interpolated between different cities.

Transmission is modeled as 134 nodes with 300 separate corridors for the contiguous 48 states. Each corridor is assigned a nominal carrying capacity limit. ReEDS includes the cost of spur lines to connect new renewable capacity to the transmission network, however no new node-tonode pathways are built. ReEDS tracks transmission flows due to dispatched generation, contracted operating reserves, and firm power contracts in every time-slice. Transmission cost estimates come from interconnection planning studies compiled by NREL.

Electricity prices are wholesale, calculated as annualized capital costs plus annual fuel and O\&M costs divided by annual load (that is, a levelized cost of energy basis). Capital costs are annualized by multiplying capital expenditures by a capital recovery factor, assuming a 20-year lifespan for the capital investment. Government transfers are included in the price estimates, so prices are reduced by tax subsidies and increased by payments for the carbon tax or for the ACP in the hybrid $100 \%$ CES.

ReEDS 2020 does not include a demand module so mReEDS does not incorporate demand-side responses, thus total demand is set exogenously.

\subsection{Demand, fuel, and technology cost assumptions}

We consider two demand scenarios and five fuel/technology cost scenarios. 
The reference and high electrification demand scenarios come from NREL (2018). The reference electricity demand is very similar to EIA AEO (2021). ${ }^{6}$ Total demand in the high electrification scenario is $8 \%$ greater than the reference case in 2030 and is $15 \%$ greater in $2035 .^{7}$

The five fuel and technology cost scenarios are low natural gas prices and low renewables costs, low natural gas prices and high renewables costs, reference natural gas prices and reference renewables costs, high natural gas prices and low renewables costs, and high natural gas prices and high renewables costs. The natural gas price scenarios come from EIA AEO (2020). ${ }^{8}$ The alternative renewable cost scenarios come from NREL ATB (2020); see NREL (2020). The renewable cost scenarios reflect various pathways for future cost reductions in capital costs and fixed operating costs, along with future efficiency improvements in capacity factor for the time period 2020 to 2035. Although we refer to these as low, reference, and high renewable technology costs, all of the scenarios project reductions in renewables costs. Thus, the renewable technology cost scenarios only differ by the extent of those reductions. ${ }^{9}$

\footnotetext{
${ }^{6}$ For example, the NREL base electrification scenario has total load of 4,302 BkWh in 2030 and 4,407 BkWh in 2035 while EIA AEO2021 has total load of 4242.9 BkWh in 2030 and $4406.7 \mathrm{BkWh}$ in 2035.

${ }^{7}$ The reference scenario reflects an increase in electric space heating from 12\% in 2018 to $17 \%$ in 2050, no change in electric water heating, an increase in electric vehicles from $<1 \%$ to $11 \%$ of the light-duty fleet, and no change in industrial curing. We also consider a high electrification scenario which reflects an increase in electric space heating from $12 \%$ in 2018 to $61 \%$, an increase in electric water heating from $26 \%$ to $52 \%$, an increase in electric vehicles from $<1 \%$ to $84 \%$ of the light-duty fleet, and an increase from $0 \%$ to $63 \%$ in electricity's share of industrial curing, all by 2050 .

${ }^{8}$ The low natural gas price scenario reflects EIA's high oil and gas supply scenario with natural gas prices increasing from $\$ 2.46 / \mathrm{MMBTU}$ in 2020 to $\$ 2.61 / \mathrm{MMBTU}$ in 2035. The reference natural gas price scenario reflects EIA's reference oil and gas supply scenario with natural gas prices increasing from \$2.46/MMBTU in 2020 to $\$ 3.36 / \mathrm{MMBTU}$ in 2035. The high natural gas price scenario reflects EIA's low oil and gas supply scenario with natural gas prices increasing from \$2.63/MMBTU in 2020 to \$5.15/MMBTU in 2035 .

${ }^{9}$ The low cost renewables pathway assumes a 52\% decline in capital costs and a $23 \%$ increase in capacity factor for utility-scale solar, a $46 \%$ decline in capital costs and a $16 \%$ increase in capacity factor for on-shore wind turbines, and a 57\% decline in capital costs for battery storage from 2020 to 2035. The reference cost renewables pathway assumes a $41 \%$ decline in capital costs and a $12 \%$ increase in capacity factor for utility-scale solar, a $27 \%$ decline in capital costs and a $9.7 \%$ increase in capacity factor for on-shore wind turbines, and a $47 \%$ decline in capital costs for battery storage from 2020 to 2035. The high cost renewables pathway assumes a $27 \%$ decline in capital costs and a $6 \%$ increase in capacity factor for utility-scale solar, a $18 \%$ decline in capital costs and a $3.1 \%$ increase in capacity factor for on-shore wind turbines, and a $28 \%$ decline in capital costs for battery storage from 2020 to 2035 .
} 


\section{Climate Policies}

Table 1 summarizes the policies studied in this paper.

Table 1. Modeled Climate Policies

\begin{tabular}{|c|c|}
\hline Policy & Description \\
\hline $90 \% \mathrm{CES}$ & $\begin{array}{l}\text { National clean electricity standard, starting at } 38 \% \text { non-fossil in } 2022 \text {, } \\
\text { increasing linearly to } 90 \% \text { in } 2035.90 \% \text { partial crediting for CCS, no } \\
\text { partial crediting for gas generation. }\end{array}$ \\
\hline $\begin{array}{l}\text { 100\% CES with } \\
\$ 40 \text { APS }\end{array}$ & $\begin{array}{l}\text { National CES, starting at } 48 \% \text { non-fossil generation in } 2022 \text {, } \\
\text { increasing linearly to } 80 \% \text { in } 2030 \text {, then increasing linearly to } 100 \% \text { in } \\
2035 \text {. Partial crediting with benchmark intensity factor } 1.0 \text { mton } \\
\mathrm{CO}_{2} / \mathrm{MWh} \text {. Compliance is by retiring clean energy credits or through } \\
\text { making alternative compliance payments (ACP) at } \$ 40 / \text { ton } \mathrm{CO}_{2} \\
\text { starting in } 2022 \text { and increasing } 3 \% / \text { year. }\end{array}$ \\
\hline $\begin{array}{l}100 \% \text { CES with } \\
\$ 20 \text { APS }\end{array}$ & $\begin{array}{l}\text { Same as hybrid } 100 \% \text { CES but with } \$ 20 / \text { ton } \mathrm{CO}_{2} \mathrm{ACP} \text { starting in } \\
2022 \text { and increasing } 3 \% / \text { year. }\end{array}$ \\
\hline TPS & $\begin{array}{l}\text { National tradable performance standard that imposes a national } \\
\text { emissions rate cap starting at } 0.33 \text { tons } \mathrm{CO}_{2} / \mathrm{MWh} \text { in } 2022 \text {, decreasing } \\
\text { linearly to } 0.04 \text { ton } \mathrm{CO}_{2} / \mathrm{MWh} \text { in } 2035 \text {. All generators receive partial } \\
\text { crediting in proportion to } \mathrm{CO}_{2} \text { emissions rate. }\end{array}$ \\
\hline$\$ 40$ Carbon tax & National carbon tax, starting at $\$ 40$ in 2022 , increasing $3 \%$ per year. \\
\hline$\$ 20$ Carbon tax & National carbon tax, starting at \$20 in 2022, increasing 3\% per year. \\
\hline PTC/ITC extension & $\begin{array}{l}\text { Extension of the } \$ 24 / \mathrm{MWh} \text { production tax credit (indexed to } \\
\text { inflation), } 30 \% \text { investment tax credit through } 2035 \text {, and } 45 \mathrm{Q} \text { tax credit } \\
\text { for CCS. }\end{array}$ \\
\hline State CES & $\begin{array}{l}\text { CA, CO, CT, MA, MD, ME, NJ, NM, NY, NV, OR, RI, WA, VA, and } \\
\text { VT adopt an accelerated state clean electricity standard which } \\
\text { increases linearly to } 100 \% \text { clean electricity by } 2035 . \text { No partial } \\
\text { crediting for gas generation. }\end{array}$ \\
\hline $\begin{array}{l}\text { Hybrid } 100 \% \text { CES } \\
\text { with } \$ 40 \mathrm{ACP}+ \\
\text { PTC/ITC extension }\end{array}$ & Combines hybrid 100\% CES (\$40 ACP) with PTC/ITC extension. \\
\hline $\begin{array}{l}\text { State CES + } \\
\text { PTC/ITC extension }\end{array}$ & Combines state CES policies with PTC/ITC extension. \\
\hline
\end{tabular}

Notes: All dollars are 2018 dollars.

The first three policies are variations on clean electricity standards. The first, a 90\% CES, requires $38 \%$ clean generation in 2022, increasing linearly to $90 \%$ clean generation by 2035 (so the standard is $70 \%$ clean in 2030). Awarding of clean energy credits is based on technology. Full credit is awarded to wind, solar, nuclear, hydro, biopower, and geothermal generation, and $90 \%$ credit is awarded to fossil fuel generation with carbon capture and storage (CCS). There is 
no partial crediting of gas generation. For each MWh generated, the obligated party must retire that year's percentage of clean energy credits.

The hybrid CES is a more ambitious CES, increasing linearly to an $80 \%$ clean mandate in 2030 and a $100 \%$ clean mandate in 2035 . Fossil fuel generation receives partial crediting in proportion to the carbon intensity of the generator, with a benchmark carbon intensity of 1.0 mton $\mathrm{CO}_{2} / \mathrm{MWh}$. Obligated parties can either retire that year's percentage of clean energy credits for each MWh generated, or make an ACP of $\$ 40$ per clean energy credit in 2022, increasing 3\% per year; we also consider a version with a $\$ 20$ ACP. The ACP backstop generates positive revenues for the federal government.

The Tradable Performance Standard (TPS) specifies a national average emissions rate, starting at 0.3325 tons $\mathrm{CO}_{2} / \mathrm{MWh}$ in 2022 and decreasing linearly to 0.04 tons $\mathrm{CO}_{2} / \mathrm{MWh}$ in 2035 . Tradable allowances must be retired in proportion to an obligated party's carbon emissions rate. A TPS could be implemented legislatively, however because it directly targets $\mathrm{CO}_{2}$ emissions, we also interpret it as an idealized version of what might be achievable by power sector $\mathrm{CO}_{2}$ regulation under the Clean Air Act. ${ }^{10}$

The next two policies are a $\$ 40$ and $\$ 20$ carbon tax (2018 dollars) that increase at 3\% annually in real terms. Because we only model the power sector, the results are the same for an economywide tax or a tax on power sector emissions only. The carbon tax produces revenues for the Federal government. We model those revenues as not flowing directly back into the power sector, so because the model is partial equilibrium, the disposition of the tax receipts does not matter for emissions or prices.

The tax credit extension consists of continuing the 30\% ITC (an expansion from the current 26\% ITC) and the \$24/MWh PTC for all currently qualifying technologies. New solar photovoltaic, offshore wind, and concentrated solar power technologies qualify for the ITC. New hydroelectric, onshore wind, geothermal and biopower technologies qualify for the PTC. Additionally, the 45Q tax credit for coal and natural gas CCS is extended through 2035.

We also consider a policy in which there is no federal action, but some states implement more ambitious state-level plans. Specifically, we suppose that the 14 states with existing CES policies

\footnotetext{
${ }^{10}$ With the remand of the Affordable Clean Energy rule by the DC Circuit Court of Appeals (American Lung Association v. EPA, No. 19-1140, D.C. Cir. 2021), the Environmental Protection Agency has the opportunity to craft a replacement to the Clean Power Plan and the Affordable Clean Energy rules. The DC Circuit judgement appears to open the door to using an emissions-based trading system as the best system of emissions reductions (op cit., p. 49). One of the compliance options under the Clean Power Plan was rate-based regulation with intrastate trading. Because the regulated pollutant is $\mathrm{CO}_{2}$, compliance through a performance standard with interstate trading, covering both new and existing sources, might have broad similarities to the TPS modeled here.
} 
or ambitious RPS policies ${ }^{11}$ - California, Colorado, Connecticut, Massachusetts, Maryland, Maine, New Jersey, New Mexico, New York, Nevada, Oregon, Washington, Virginia and Vermont - increase ambition to $100 \%$ clean energy generation within state boundaries by 2035 , starting from $38 \%$ clean in 2022 and increasing linearly, with no partial crediting of gas generation and $90 \%$ partial crediting of CCS. ACP rules follow each state's existing laws. ${ }^{12}$

Finally, we consider two combination policies: extending the PTC/ITC plus the hybrid 100\% CES with \$40 ACP, and extending the PTC/ITC plus enhanced state CES,

These policies are compared to a business-as-usual (BAU) scenario, in which the ITC and PTC phase down according to current law, there is no new federal policy, and state RPS and CES policies remain as specified under 2020 state laws.

\section{Results}

We begin with the carbon dioxide emissions under each policy, before turning to system costs, federal expenditures, and regional impacts. All results are simulated in mReEDS.

\subsection{Baseline, carbon tax, and sectoral standards}

Figure 1 presents annual carbon dioxide emissions by climate policy for all policies for all ten demand/price scenarios, along with thresholds for $80 \%, 85 \%, 90 \%$, and $95 \%$ power sector emissions reductions, relative to 2005. Figure 2 show national average wholesale electricity prices by climate policy.

Table 2 and Table 3 summarizes abated emissions and average abatement cost for each policy for the low and high demand scenarios, respectively. The average abatement cost is the total change in system costs, divided by the tons of $\mathrm{CO}_{2}$ emissions abated, both in comparison to BAU under the stated technology and gas price assumptions. ${ }^{13}$ The table also presents the cost per ton of the efficient policy that achieves the same emissions path, which in this deterministic model is a cap-and-trade policy (or, equivalently, a carbon tax); comparing the cost per ton of the proposed policy to the emissions-equivalent efficient policy provides an estimate of the cost

\footnotetext{
11 “Ambitious RPS policies" are defined as RPS policies that require at least 30\% generation from renewable technologies by 2035 .

${ }^{12}$ If a state has no ACP, the ACP is set at \$200/MWh.

${ }^{13}$ Additional system costs are those privately borne (post-ITC capital costs, O\&M, fuel, and transmission costs) plus federal ITC/PTC tax expenditures, on a per-ton abated basis. This measure reflects all direct costs associated with the bulk electricity system. System costs do not include carbon tax or ACP payments to the federal government.
} 
effectiveness of the proposed policy. ${ }^{14}$ Figure 3 shows annual average generation by source, as changes from BAU.

A striking feature of the BAU projections (Figure 1(a)) is the wide range of projections, depending on the demand/price scenario. If renewables prices are low, then the model projects significant (but not deep) decarbonization without additional policy, however without those tailwinds, emissions decline only slightly or not at all. Under BAU, power sector $\mathrm{CO}_{2}$ emissions fall gradually under the reference scenario as the cost of renewables declines and renewables displace some coal and gas. By 2035, emissions are projected to be $47 \%$ below 2005 levels under BAU. This projection is comparable to the $46 \%$ projected decline in emissions under the EIA AEO (2020) reference case, however emissions fall by $51 \%$ under the EIA AEO (2021) reference case. Under the reference scenario, only $32 \mathrm{GW}$ of wind and $24 \mathrm{GW}$ of natural gas are built between 2022-2026 (recall that the ITC and PTC expire under the baseline). As a result, coal generation is relatively constant from 2026 through 2038. The reference scenario has flat or slightly decreasing average wholesale electricity prices through 2038 (Figure 2).

Standards and carbon taxes. Looking across all policies, the only two that robustly produce at least $80 \%$ decarbonization are the TPS and the hybrid $100 \%$ CES with a \$40 ACP. The \$20 carbon tax and the other standards (the 90\% CES and the hybrid CES with \$20 ACP) each achieve deep decarbonization in some price scenarios, but not all. The reasons for this result are sometimes subtle, so we consider the policies one by one.

The tradeable performance standard has the most reliable reduction in emissions, with emissions reductions (relative to 2005) of $85 \%-89 \%$ across all ten scenarios. The reason for this robust performance is that the TPS mandates an emission rate, and the price of the tradeable permit adjusts depending on cost conditions. Accordingly, the average abatement cost for the TPS ranges from $\$ 15$ to $\$ 32 /$ ton, with the prices lowest when gas is inexpensive and renewables costs are high. The TPS is essentially as economically efficient as the emissions-equivalent massbased cap and trade system.

\footnotetext{
14 There are several surprising cap-and-trade results under certain technology cost assumptions, including negative average abatement costs at low levels of abatement and higher system costs under a cap-and-trade than a tradeable performance standard. These results are due to myopic expectations, which allows for the possibility of mistakes in that sequential cost-minimization can lead to higher costs than decisions made under perfect foresight. See the Appendix for further discussion.
} 
Figure 1. Annual Carbon Emissions by Climate Policy
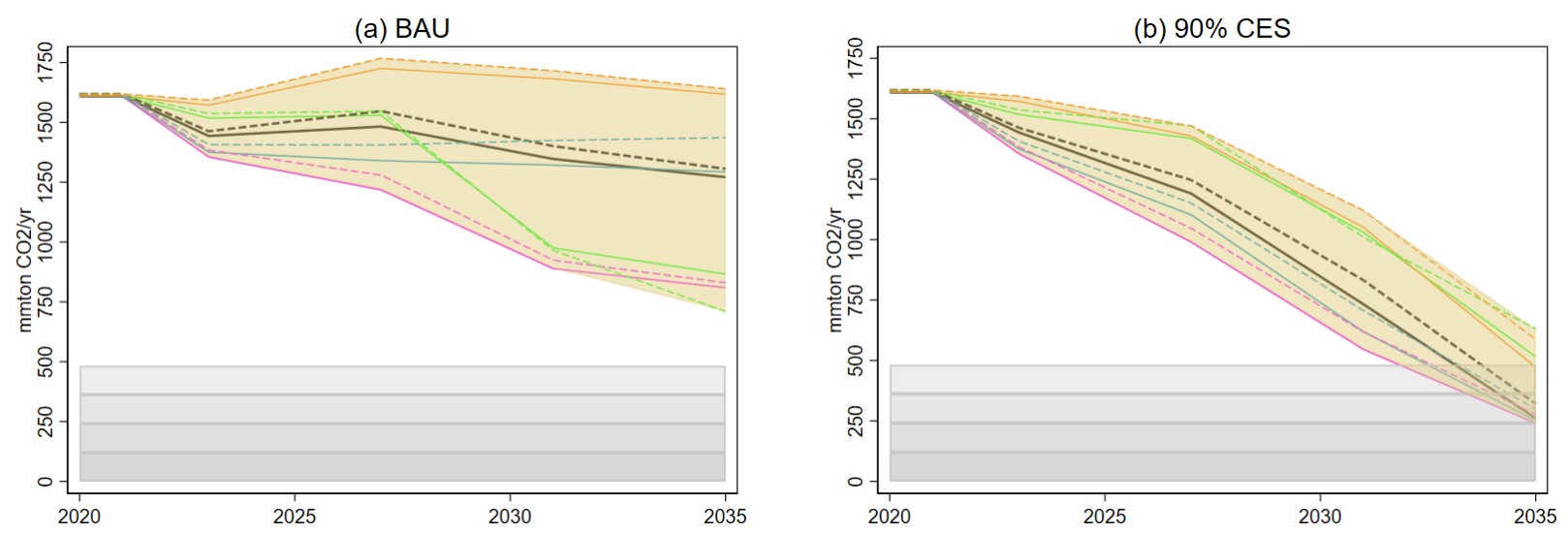

(c) Hybrid $100 \%$ CES $(\$ 40$ ACP)

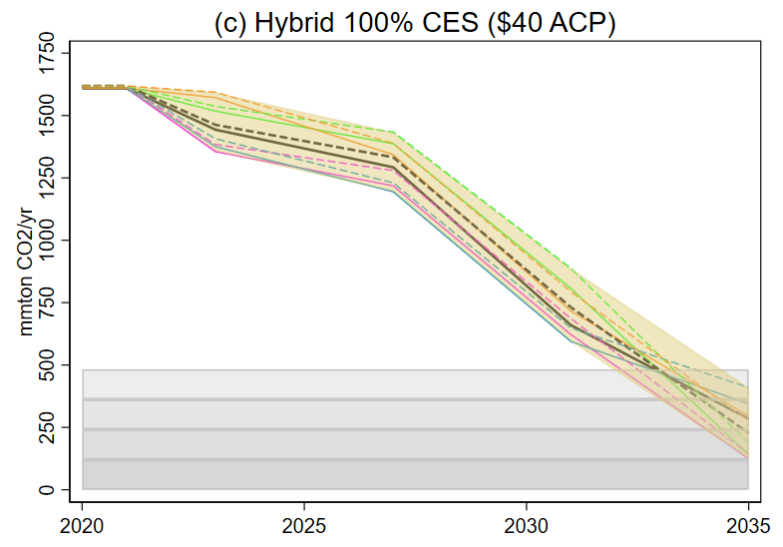

(d) TPS

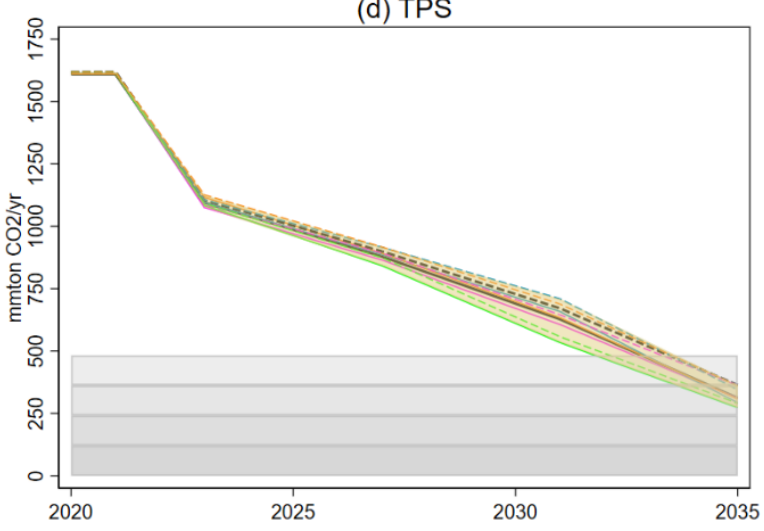

(e) Tax Credit Extension
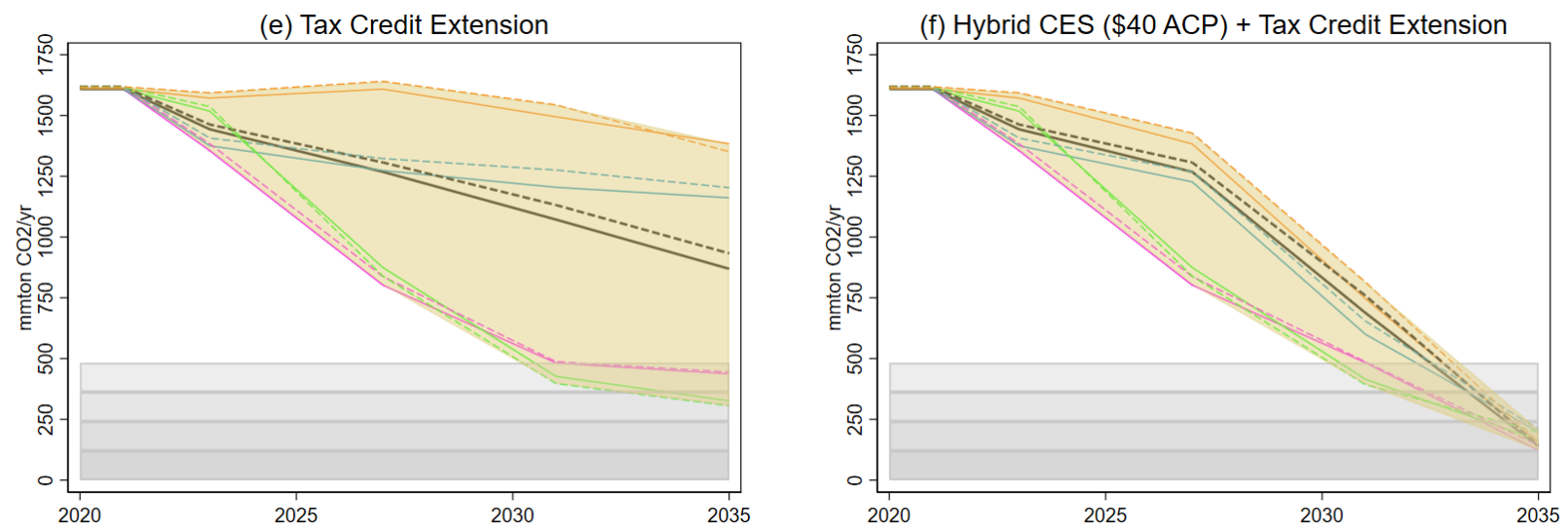

$\begin{array}{lllll}\text { - LoD-Ref } & - \text { LoD-LoG-LoR } & - \text { LoD-LoG-HiR } & - \text { LoD-HiG-LoR } & - \text { LoD-HiG-HiR } \\ \text {-- HiD-Ref } & -- \text { HiD-LoG-LoR } & -- \text { HiD-LoG-HiR } & -- \text { HiD-HiG-LoR } & -- \text { HiD-HiG-HiR }\end{array}$

Notes: The policies are described in Table 1. Scenarios in the legend are low/high demand, low/reference/high natural gas price, low/reference/high renewables prices. Gray shading denotes $80 \%$, $85 \%, 90 \%, 95 \%$ emissions reductions, relative to 2005 . Source: mReEDS model and authors' calculations. 
Figure 1, continued

(g) Hybrid 100\% CES (\$20 ACP)

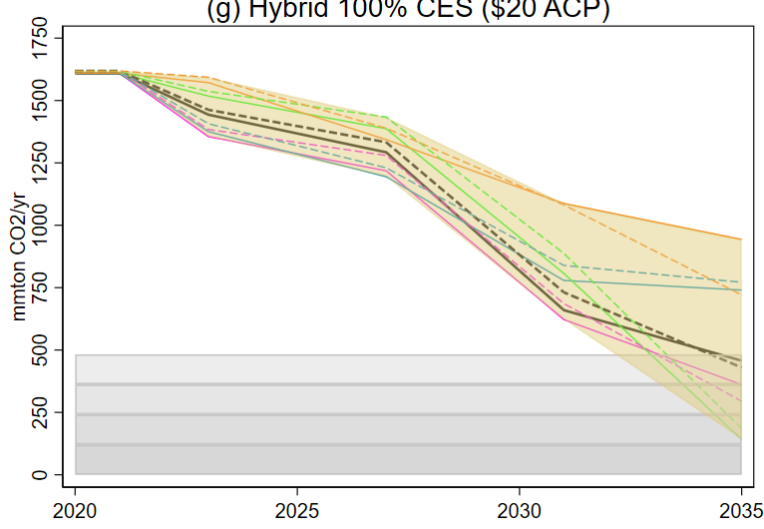

(i) $\$ 20$ Carbon Tax

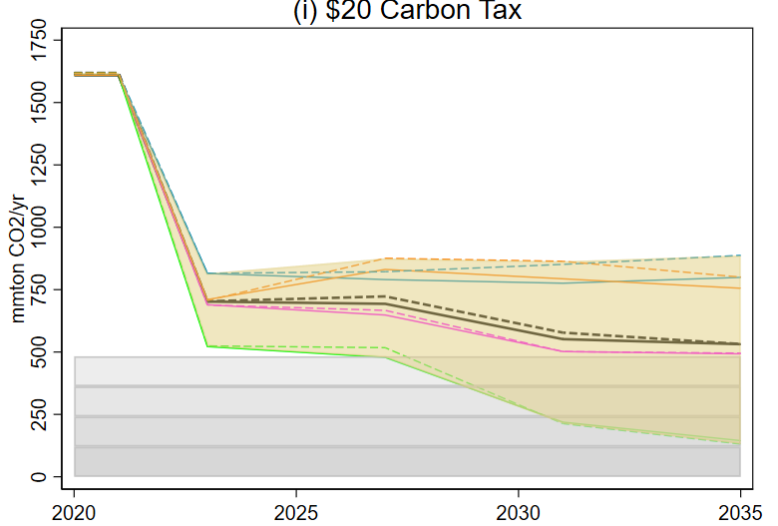

(k) State CES + Tax Credit Extension

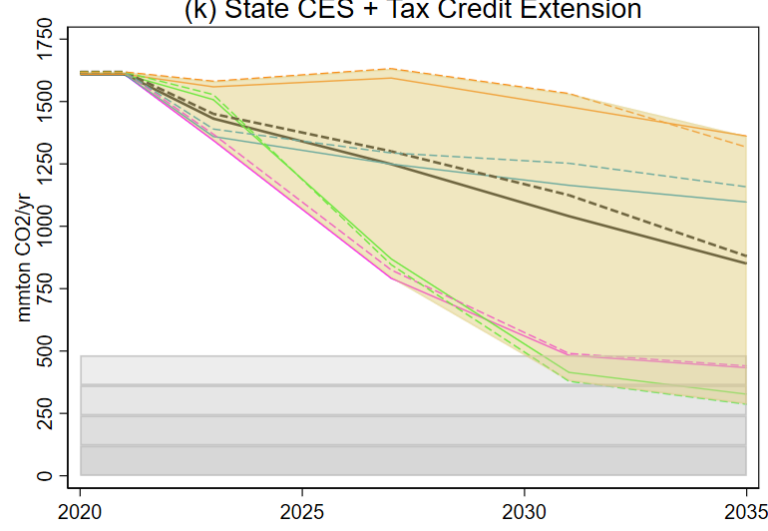

(h) $\$ 40$ Carbon Tax

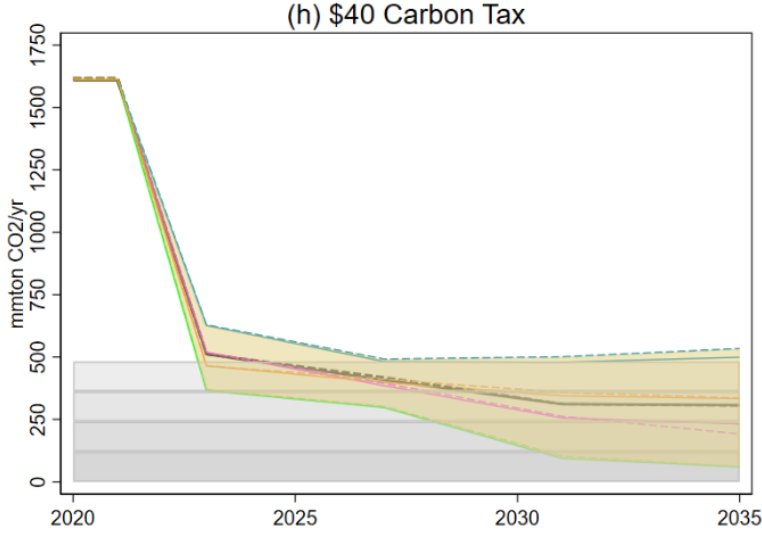

(j) State CES

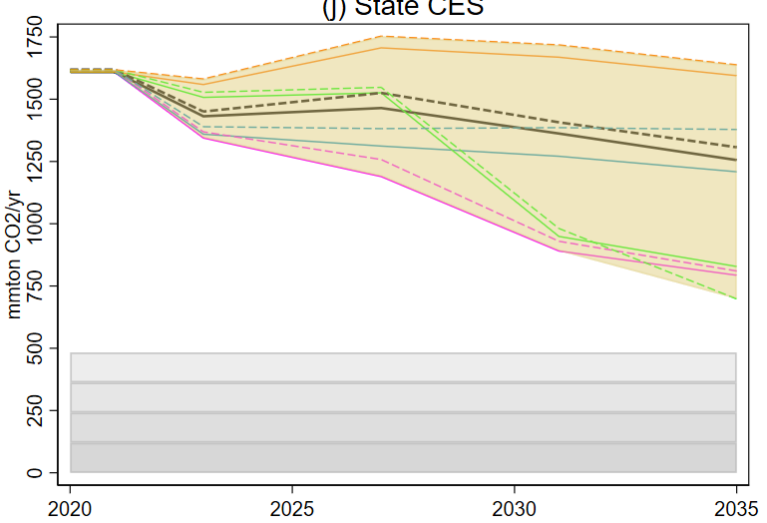

\section{- LoD-Ref - LoD-LoG-LoR - LoD-LoG-HiR - LoD-HiG-LoR - LoD-HiG-HiR \\ -- HiD-Ref -- HiD-LoG-LoR -- HiD-LoG-HiR -- HiD-HiG-LoR -- HiD-HiG-HiR}

Notes: The policies are described in Table 1. Scenarios in the legend are low/high demand,

low/reference/high natural gas price, low/reference/high renewables prices. Gray shading denotes $80 \%$, $85 \%, 90 \%, 95 \%$ emissions reductions, relative to 2005 . Source: mReEDS model and authors' calculations. 
Figure 2. National Average Wholesale Electricity Prices, by Climate Policy

(a) BAU

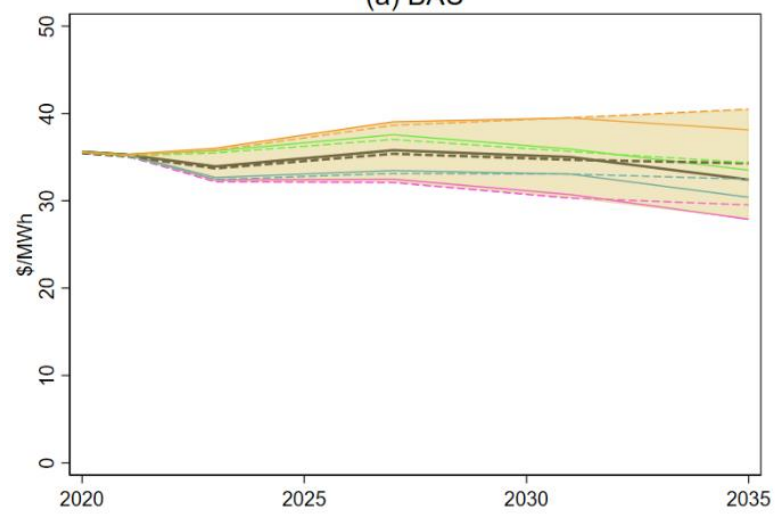

(c) Hybrid $100 \%$ CES $(\$ 40$ ACP)

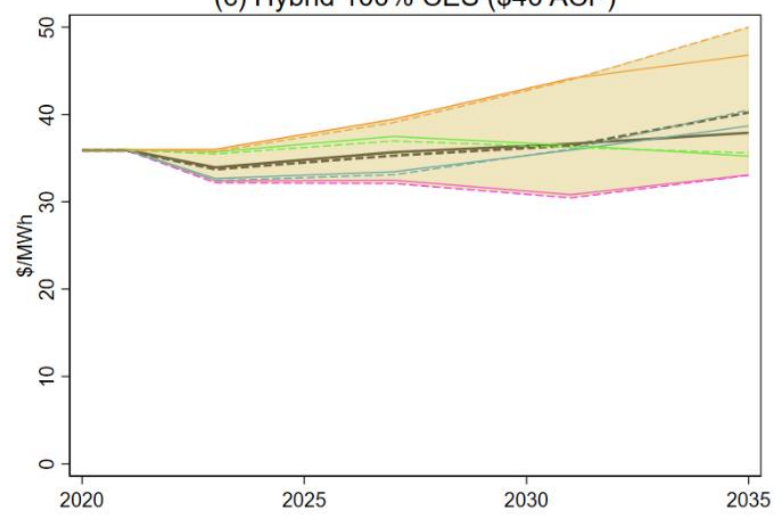

(e) Tax Credit Extension

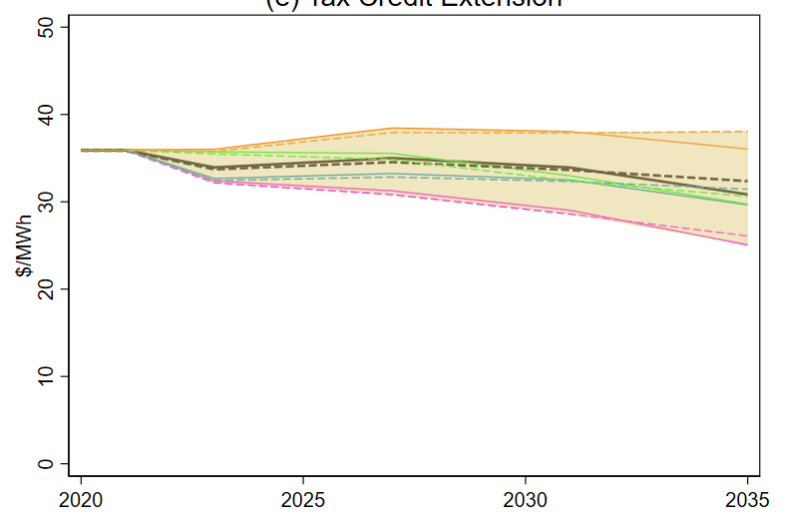

(b) $90 \%$ CES

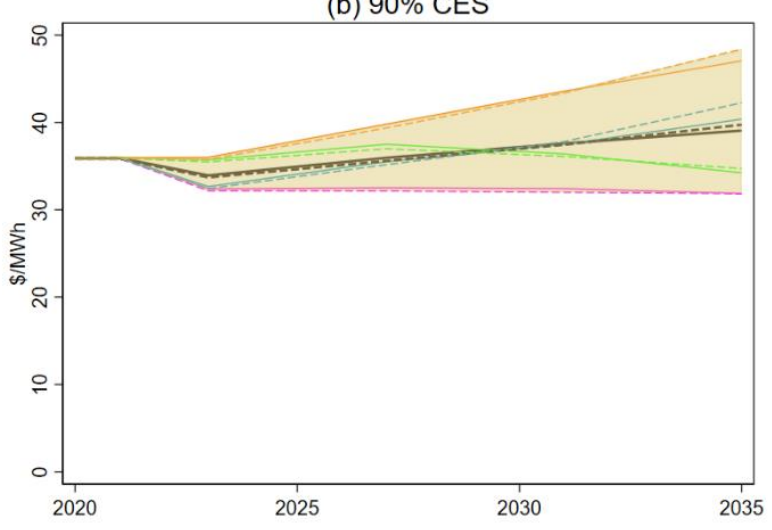

(d) TPS

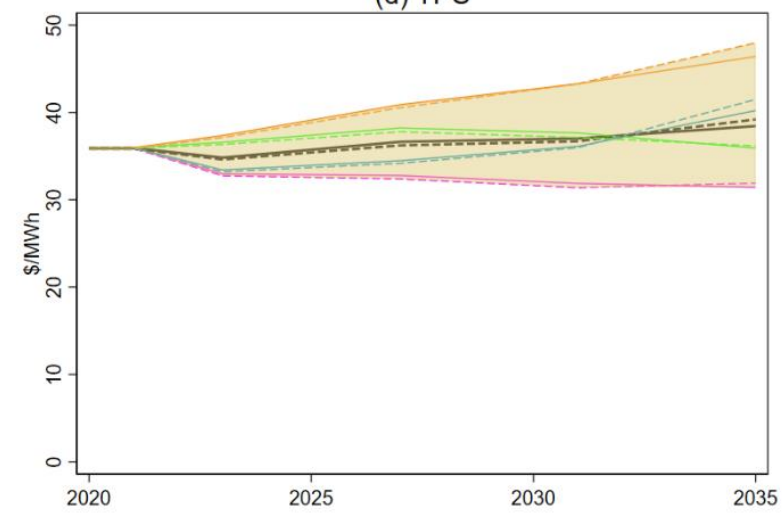

(f) Hybrid CES (\$40 ACP) + Tax Credit Extension

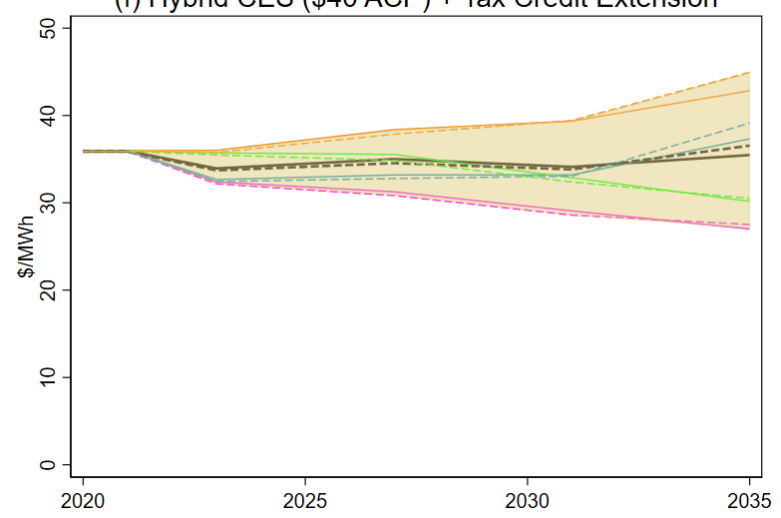

\section{- LoD-Ref - LoD-LoG-LoR - LoD-LoG-HiR - LoD-HiG-LoR - LoD-HiG-HiR \\ -- HiD-Ref -- HiD-LoG-LoR -- HiD-LoG-HiR -- HiD-HiG-LoR - - HiD-HiG-HiR}

Notes: The policies are described in Table 1. Scenarios in the legend are low/high demand, low/reference/high natural gas price, low/reference/high renewables prices. Source: mReEDS model and authors' calculations. 
Figure 2, continued

(g) Hybrid 100\% CES (\$20 ACP)

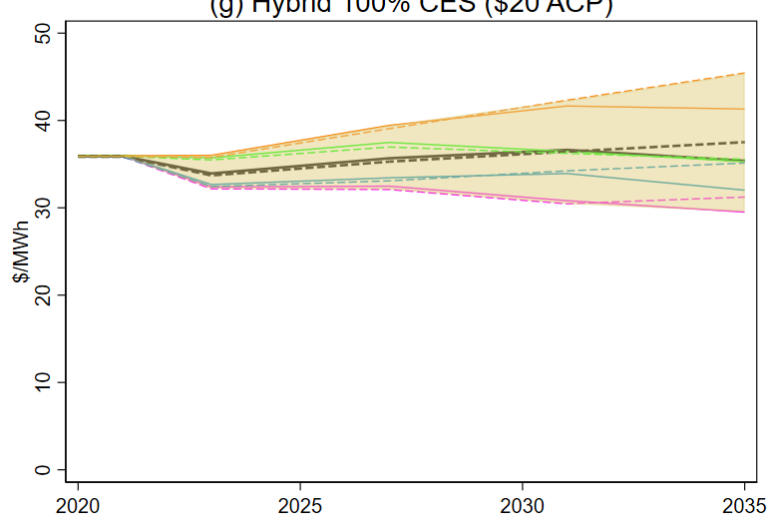

(i) $\$ 20$ Carbon Tax

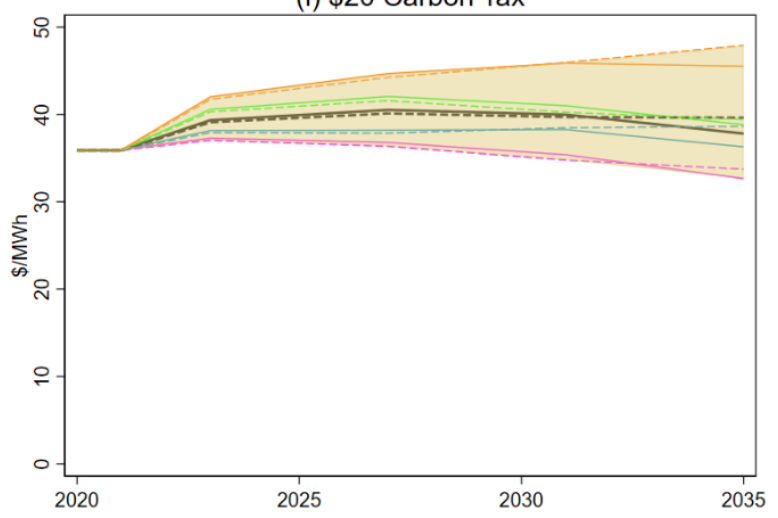

(h) $\$ 40$ Carbon Tax

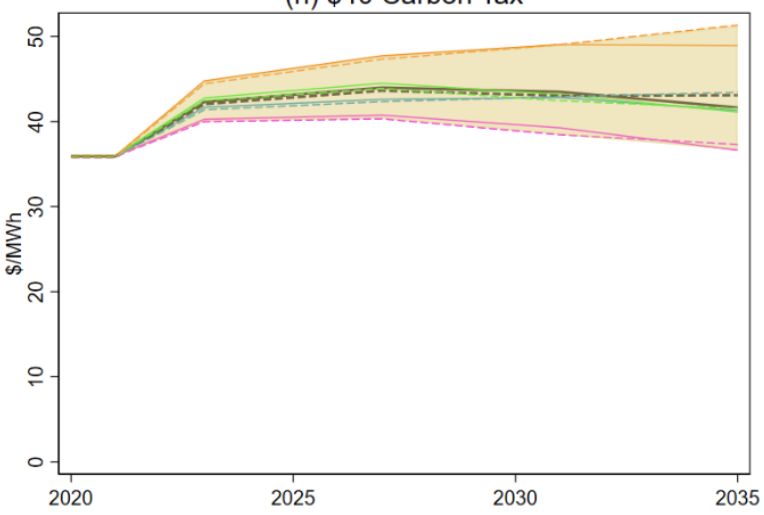

(j) State CES

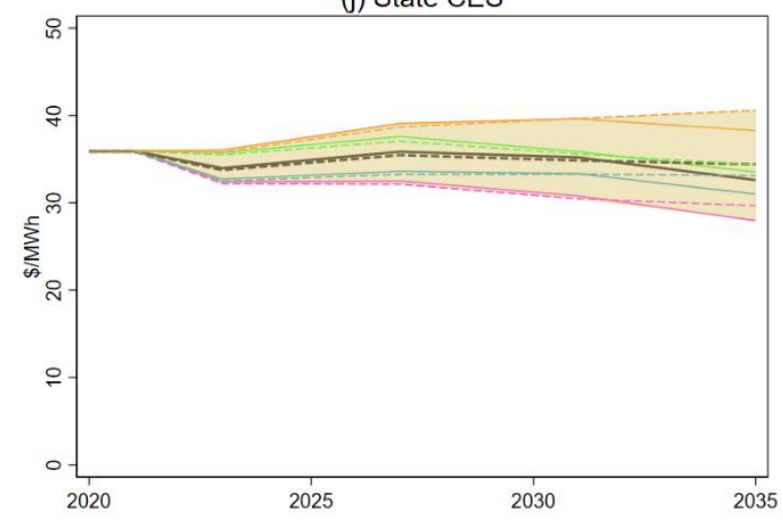

(k) State CES + Tax Credit Extension

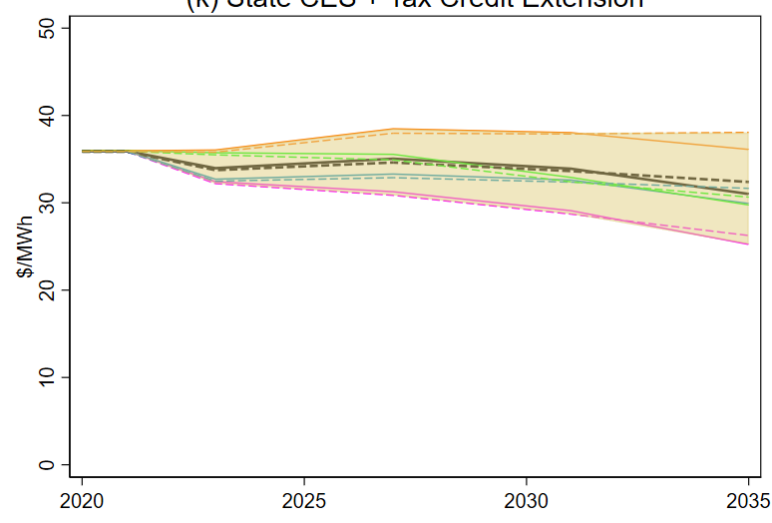

$\begin{array}{lllll}\text { - LoD-Ref } & - \text { LoD-LoG-LoR } & - \text { LoD-LoG-HiR } & - \text { LoD-HiG-LoR } & - \text { LoD-HiG-HiR } \\ \text {-- HiD-Ref } & -- \text { HiD-LoG-LoR } & -- \text { HiD-LoG-HiR } & -- \text { HiD-HiG-LoR } & -- \text { HiD-HiG-HiR }\end{array}$

Notes: The policies are described in Table 1. Scenarios in the legend are low/high demand, low/reference/high natural gas price, low/reference/high renewables prices. Source: mReEDS model and authors' calculations. 
Table 2. Abatement and Average Abatement Costs: Low Demand

\begin{tabular}{|c|c|c|c|c|c|c|}
\hline Climate Policy & $\begin{array}{c}\text { Annual CO2 } \\
\text { Emissions in } \\
2035\end{array}$ & $\begin{array}{l}2035 \text { Emissions } \\
\text { as fraction of } \\
2005 \text { Emissions }\end{array}$ & $\begin{array}{l}\text { Cumulative } \\
\text { Abatement }\end{array}$ & $\begin{array}{c}\text { Average } \\
\text { Abatement } \\
\text { Cost } \\
\end{array}$ & $\begin{array}{c}\text { Average } \\
\text { Abatement Cost, } \\
\text { Equivalent C\&T }\end{array}$ & $\begin{array}{c}\text { Cost ratio: } \\
\text { Policy to } \\
\text { C\&T }\end{array}$ \\
\hline \multicolumn{7}{|l|}{ Reference Technology Scenario: } \\
\hline BAU & 1,271 & 0.526 & - & - & - & - \\
\hline$\$ 20$ Carbon Tax & 531 & 0.220 & 12,260 & $\$ 12.9$ & $\$ 12.9$ & 1.00 \\
\hline$\$ 40$ Carbon Tax & 307 & 0.127 & 16,020 & $\$ 22.9$ & $\$ 22.9$ & 1.00 \\
\hline TPS & 312 & 0.129 & 10,526 & $\$ 19.8$ & $\$ 19.2$ & 1.03 \\
\hline $90 \% \mathrm{CES}$ & 261 & 0.108 & 7,665 & $\$ 23.9$ & $\$ 21.3$ & 1.12 \\
\hline $100 \%$ Hybrid CES, \$20 ACP & 457 & 0.189 & 6,764 & $\$ 11.3$ & $\$ 10.7$ & 1.05 \\
\hline $100 \%$ Hybrid CES, \$40 ACP & 284 & 0.118 & 7,455 & $\$ 19.8$ & $\$ 19.1$ & 1.04 \\
\hline PTC/ITC Extension & 869 & 0.360 & 3,565 & $\$ 35.4$ & $\$ 4.4$ & 8.14 \\
\hline State CES & 1,256 & 0.520 & 119 & $\$ 81.0$ & $-*$ & $-*$ \\
\hline PTC/ITC Extension and State CES & 850 & 0.352 & 3,888 & $\$ 33.5$ & $\$ 4.3$ & 7.73 \\
\hline $100 \%$ Hybrid CES $(\$ 40$ ACP $)+$ Extension & 139 & 0.057 & 8,021 & $\$ 52.9$ & $\$ 30.0$ & 1.76 \\
\hline \multicolumn{7}{|l|}{ Low renewables/low gas price scenario } \\
\hline BAU & 809 & 0.335 & - & - & & - \\
\hline \$20 Carbon Tax & 493 & 0.204 & 7,758 & $\$ 20.5$ & $\$ 20.8$ & 0.99 \\
\hline$\$ 40$ Carbon Tax & 232 & 0.096 & 11,522 & $\$ 34.6$ & $\$ 34.7$ & 1.00 \\
\hline TPS & 310 & 0.128 & 5,661 & $\$ 23.2$ & $\$ 21.3$ & 1.09 \\
\hline $90 \% \mathrm{CES}$ & 241 & 0.100 & 4,558 & $\$ 24.7$ & $\$ 21.8$ & 1.13 \\
\hline $100 \%$ Hybrid CES, \$20 ACP & 361 & 0.149 & 2,860 & $\$ 14.4$ & $\$ 14.6$ & 0.99 \\
\hline $100 \%$ Hybrid CES, $\$ 40$ ACP & 124 & 0.051 & 3,809 & $\$ 37.2$ & $\$ 35.9$ & 1.03 \\
\hline PTC/ITC Extension & 437 & 0.181 & 4,782 & $\$ 71.0$ & $\$ 11.0$ & 6.46 \\
\hline State CES & 793 & 0.328 & 219 & $\$ 23.7$ & $\$ 23.8$ & 0.99 \\
\hline PTC/ITC Extension and State CES & 433 & 0.179 & 4,880 & $\$ 67.4$ & $\$ 11.4$ & 5.92 \\
\hline $100 \%$ Hybrid CES $(\$ 40$ ACP $)+$ Extension & 123 & 0.051 & 6,033 & $\$ 87.6$ & $\$ 30.4$ & 2.88 \\
\hline \multicolumn{7}{|l|}{$\underline{\text { High renewables/low gas price scenario }}$} \\
\hline $\mathrm{BAU}$ & 1,293 & 0.535 & - & - & & - \\
\hline \$20 Carbon Tax & 799 & 0.331 & 8,600 & $\$ 8.5$ & $\$ 8.5$ & 1.00 \\
\hline$\$ 40$ Carbon Tax & 499 & 0.207 & 12,973 & $\$ 22.8$ & $\$ 22.9$ & 1.00 \\
\hline TPS & 293 & 0.121 & 9,588 & $\$ 31.7$ & $\$ 28.8$ & 1.10 \\
\hline $90 \% \mathrm{CES}$ & 251 & 0.104 & 7,928 & $\$ 39.5$ & $\$ 35.9$ & 1.10 \\
\hline $100 \%$ Hybrid CES, \$20 ACP & 740 & 0.306 & 4,963 & $\$ 7.8$ & $\$ 7.1$ & 1.09 \\
\hline $100 \%$ Hybrid CES, $\$ 40$ ACP & 344 & 0.143 & 7,285 & $\$ 32.4$ & $\$ 31.5$ & 1.03 \\
\hline PTC/ITC Extension & 1,161 & 0.481 & 1,261 & $\$ 19.2$ & $-*$ & $-*$ \\
\hline State CES & 1,209 & 0.500 & 716 & $\$ 30.7$ & $-*$ & $-*$ \\
\hline PTC/ITC Extension and State CES & 1,097 & 0.454 & 1,839 & $\$ 26.2$ & $-*$ & $-*$ \\
\hline $100 \%$ Hybrid CES $(\$ 40$ ACP $)+$ Extension & 198 & 0.082 & 7,718 & $\$ 51.0$ & $\$ 41.3$ & 1.23 \\
\hline
\end{tabular}


Table 2, continued

\begin{tabular}{|c|c|c|c|c|c|c|}
\hline Climate Policy & $\begin{array}{c}\text { Annual CO2 } \\
\text { Emissions in } \\
2035\end{array}$ & $\begin{array}{c}2035 \text { Emissions } \\
\text { as fraction of } \\
2005 \text { Emissions }\end{array}$ & $\begin{array}{l}\text { Cumulative } \\
\text { Abatement }\end{array}$ & $\begin{array}{c}\text { Average } \\
\text { Abatement } \\
\text { Cost } \\
\end{array}$ & $\begin{array}{c}\text { Average } \\
\text { Abatement Cost, } \\
\text { Equivalent C\&T }\end{array}$ & $\begin{array}{l}\text { Cost ratio: } \\
\text { Policy to } \\
\text { C\&T }\end{array}$ \\
\hline \multicolumn{7}{|l|}{ Low renewables/high gas price scenario } \\
\hline BAU & 866 & 0.359 & - & - & & - \\
\hline$\$ 20$ Carbon Tax & 145 & 0.060 & 14,101 & $\$ 22.3$ & $\$ 22.3$ & 1.00 \\
\hline$\$ 40$ Carbon Tax & 60 & 0.025 & 16,291 & $\$ 28.9$ & $\$ 28.9$ & 1.00 \\
\hline TPS & 273 & 0.113 & 8,626 & $\$ 15.2$ & $\$ 16.5$ & 0.92 \\
\hline $90 \% \mathrm{CES}$ & 516 & 0.213 & 1,628 & $\$ 11.5$ & $\$ 8.7$ & 1.32 \\
\hline $100 \%$ Hybrid CES, \$20 ACP & 142 & 0.059 & 4,142 & $\$ 10.3$ & $\$ 9.5$ & 1.09 \\
\hline $100 \%$ Hybrid CES, $\$ 40$ ACP & 142 & 0.059 & 4,140 & $\$ 10.0$ & $\$ 9.1$ & 1.10 \\
\hline PTC/ITC Extension & 326 & 0.135 & 6,976 & $\$ 64.2$ & $\$ 9.1$ & 7.06 \\
\hline State CES & 828 & 0.343 & 315 & $\$ 2.0$ & $-*$ & $-*$ \\
\hline PTC/ITC Extension and State CES & 327 & 0.135 & 7,084 & $\$ 61.6$ & $\$ 9.5$ & 6.49 \\
\hline $100 \%$ Hybrid CES ( $\$ 40 \mathrm{ACP})+$ Extension & 163 & 0.068 & 7,675 & $\$ 64.7$ & $\$ 10.7$ & 6.08 \\
\hline \multicolumn{7}{|l|}{ High renewables/high gas price scenario } \\
\hline BAU & 1,618 & 0.670 & - & - & & - \\
\hline$\$ 20$ Carbon Tax & 756 & 0.313 & 14,022 & $\$ 14.3$ & $\$ 14.8$ & 0.96 \\
\hline$\$ 40$ Carbon Tax & 333 & 0.138 & 20,220 & $\$ 21.7$ & $\$ 21.8$ & 1.00 \\
\hline TPS & 308 & 0.127 & 14,585 & $\$ 21.4$ & $\$ 21.6$ & 0.99 \\
\hline $90 \% \mathrm{CES}$ & 472 & 0.195 & 8,291 & $\$ 30.9$ & $\$ 19.8$ & 1.56 \\
\hline $100 \%$ Hybrid CES, \$20 ACP & 943 & 0.390 & 6,604 & $\$ 13.1$ & $\$ 11.0$ & 1.19 \\
\hline $100 \%$ Hybrid CES, \$40 ACP & 295 & 0.122 & 10,678 & $\$ 23.6$ & $\$ 21.7$ & 1.09 \\
\hline PTC/ITC Extension & 1,384 & 0.573 & 2,150 & $\$ 41.9$ & $\$ 8.6$ & 4.85 \\
\hline State CES & 1,595 & 0.660 & 271 & $\$ 25.3$ & $\$ 26.0$ & 0.97 \\
\hline PTC/ITC Extension and State CES & 1,361 & 0.564 & 2,412 & $\$ 39.5$ & $\$ 8.3$ & 4.78 \\
\hline $100 \%$ Hybrid CES (\$40 ACP) +Extension & 154 & 0.064 & 10,964 & $\$ 45.1$ & $\$ 29.0$ & 1.55 \\
\hline \multicolumn{7}{|c|}{$\begin{array}{l}\text { Notes: Carbon dioxide emissions are expressed in millions of metric tons. Average costs are expressed in } 2018 \$ \text { per metric ton CO2 and include all privately-borne } \\
\text { system costs (defined as capital, O\&M, fuel and transmission costs) plus federal tax expenditures (defined as ITC and PTC expenditures). "Equivalent C\&T" refers to } \\
\text { a cap-and-trade policy calibrated to the emissions declines from a given climate policy. The difference in abatement cost between the carbon tax and the emissions- } \\
\text { equivalent cap \& trade fall within ReEDS numerical error. }\end{array}$} \\
\hline
\end{tabular}


Table 3. Abatement and Average Abatement Costs: High Demand

\begin{tabular}{|c|c|c|c|c|c|c|}
\hline Climate Policy & $\begin{array}{c}\text { Annual CO2 } \\
\text { Emissions in } \\
2035\end{array}$ & $\begin{array}{l}2035 \text { Emissions } \\
\text { as fraction of } \\
2005 \text { Emissions }\end{array}$ & $\begin{array}{l}\text { Cumulative } \\
\text { Abatement }\end{array}$ & $\begin{array}{c}\text { Average } \\
\text { Abatement } \\
\text { Cost } \\
\end{array}$ & $\begin{array}{c}\text { Average } \\
\text { Abatement Cost, } \\
\text { Equivalent C\&T }\end{array}$ & $\begin{array}{c}\% \\
\text { Difference }\end{array}$ \\
\hline \multicolumn{7}{|l|}{ Reference Technology Scenario: } \\
\hline BAU & 1,306 & 0.541 & - & - & - & - \\
\hline$\$ 20$ Carbon Tax & 532 & 0.220 & 12,721 & $\$ 14.6$ & $\$ 14.7$ & 1.00 \\
\hline$\$ 40$ Carbon Tax & 306 & 0.126 & 16,675 & $\$ 24.2$ & $\$ 24.2$ & 1.00 \\
\hline TPS & 363 & 0.150 & 10,711 & $\$ 18.6$ & $\$ 18.5$ & 1.01 \\
\hline $90 \% \mathrm{CES}$ & 321 & 0.133 & 7,414 & $\$ 23.4$ & $\$ 18.5$ & 1.27 \\
\hline $100 \%$ Hybrid CES, \$20 ACP & 430 & 0.178 & 7,039 & $\$ 13.7$ & $\$ 13.1$ & 1.05 \\
\hline $100 \%$ Hybrid CES, $\$ 40$ ACP & 227 & 0.094 & 7,850 & $\$ 23.5$ & $\$ 23.1$ & 1.01 \\
\hline PTC/ITC Extension & 933 & 0.386 & 3,529 & $\$ 47.6$ & $\$ 7.1$ & 6.69 \\
\hline State CES & 1,307 & 0.541 & 103 & $\$ 67.6$ & $\$ 11.4$ & 5.94 \\
\hline PTC/ITC Extension and State CES & 880 & 0.364 & 3,841 & $\$ 46.4$ & $\$ 7.5$ & 6.22 \\
\hline $100 \%$ Hybrid CES (\$40 ACP) +Extension & 143 & 0.059 & 8,179 & $\$ 61.1$ & $\$ 29.3$ & 2.09 \\
\hline \multicolumn{7}{|l|}{ Low renewables/low gas price scenario } \\
\hline BAU & 830 & 0.344 & - & - & & - \\
\hline$\$ 20$ Carbon Tax & 496 & 0.205 & 8,258 & $\$ 20.0$ & $\$ 20.2$ & 0.99 \\
\hline$\$ 40$ Carbon Tax & 192 & 0.079 & 12,201 & $\$ 35.1$ & $\$ 35.2$ & 1.00 \\
\hline TPS & 362 & 0.150 & 5,729 & $\$ 19.1$ & $\$ 17.4$ & 1.10 \\
\hline $90 \% \mathrm{CES}$ & 278 & 0.115 & 4,363 & $\$ 17.3$ & $\$ 15.1$ & 1.15 \\
\hline $100 \%$ Hybrid CES, \$20 ACP & 295 & 0.122 & 3,093 & $\$ 16.7$ & $\$ 17.0$ & 0.98 \\
\hline $100 \%$ Hybrid CES, $\$ 40$ ACP & 143 & 0.059 & 3,700 & $\$ 29.8$ & $\$ 29.9$ & 1.00 \\
\hline PTC/ITC Extension & 445 & 0.184 & 5,058 & $\$ 76.0$ & $\$ 10.5$ & 7.24 \\
\hline State CES & 810 & 0.335 & 204 & $\$ 39.4$ & $\$ 34.9$ & 1.13 \\
\hline PTC/ITC Extension and State CES & 441 & 0.182 & 5,171 & $\$ 73.8$ & $\$ 10.8$ & 6.84 \\
\hline 100\% Hybrid CES (\$40 ACP) +Extension & 142 & 0.059 & 6,270 & $\$ 92.6$ & $\$ 27.4$ & 3.38 \\
\hline \multicolumn{7}{|l|}{$\underline{\text { High renewables/low gas price scenario }}$} \\
\hline BAU & 1,436 & 0.594 & - & - & & - \\
\hline$\$ 20$ Carbon Tax & 887 & 0.367 & 9,187 & $\$ 10.9$ & $\$ 10.9$ & 1.00 \\
\hline$\$ 40$ Carbon Tax & 534 & 0.221 & 14,072 & $\$ 24.7$ & $\$ 24.8$ & 1.00 \\
\hline TPS & 345 & 0.143 & 10,387 & $\$ 31.2$ & $\$ 29.6$ & 1.05 \\
\hline $90 \% \mathrm{CES}$ & 299 & 0.124 & 8,433 & $\$ 42.1$ & $\$ 38.6$ & 1.09 \\
\hline $100 \%$ Hybrid CES, \$20 ACP & 772 & 0.319 & 5,699 & $\$ 14.6$ & $\$ 13.6$ & 1.07 \\
\hline $100 \%$ Hybrid CES, $\$ 40$ ACP & 409 & 0.169 & 7,912 & $\$ 33.8$ & $\$ 33.2$ & 1.02 \\
\hline PTC/ITC Extension & 1,203 & 0.498 & 1,856 & $\$ 38.2$ & $\$ 4.3$ & 8.80 \\
\hline State CES & 1,379 & 0.571 & 548 & $\$ 46.2$ & $\$ 2.3$ & 20.20 \\
\hline PTC/ITC Extension and State CES & 1,158 & 0.479 & 2,314 & $\$ 36.5$ & $\$ 4.2$ & 8.73 \\
\hline $100 \%$ Hybrid CES $(\$ 40$ ACP $)+$ Extension & 208 & 0.086 & 8,537 & $\$ 56.9$ & $\$ 44.6$ & 1.28 \\
\hline
\end{tabular}


Table 3, continued

\begin{tabular}{|c|c|c|c|c|c|c|}
\hline Climate Policy & $\begin{array}{c}\text { Annual CO2 } \\
\text { Emissions in } \\
2035\end{array}$ & $\begin{array}{l}2035 \text { Emissions } \\
\text { as fraction of } \\
2005 \text { Emissions }\end{array}$ & $\begin{array}{l}\text { Cumulative } \\
\text { Abatement }\end{array}$ & $\begin{array}{c}\text { Average } \\
\text { Abatement } \\
\text { Cost }\end{array}$ & $\begin{array}{c}\text { Average } \\
\text { Abatement Cost, } \\
\text { Equivalent C\&T }\end{array}$ & $\begin{array}{c}\% \\
\text { Difference }\end{array}$ \\
\hline \multicolumn{7}{|l|}{ Low renewables/high gas price scenario } \\
\hline BAU & 710 & 0.294 & - & - & & - \\
\hline$\$ 20$ Carbon Tax & 131 & 0.054 & 13,492 & $\$ 25.0$ & $\$ 25.0$ & 1.00 \\
\hline$\$ 40$ Carbon Tax & 59 & 0.024 & 15,703 & $\$ 31.5$ & $\$ 31.5$ & 1.00 \\
\hline TPS & 290 & 0.120 & 7,787 & $\$ 16.3$ & $\$ 19.9$ & 0.82 \\
\hline $90 \% \mathrm{CES}$ & 631 & 0.261 & 439 & $\$ 28.9$ & $\$ 15.2$ & 1.90 \\
\hline $100 \%$ Hybrid CES, \$20 ACP & 185 & 0.077 & 2,865 & $\$ 12.6$ & $\$ 12.8$ & 0.98 \\
\hline $100 \%$ Hybrid CES, $\$ 40$ ACP & 187 & 0.077 & 2,858 & $\$ 13.0$ & $\$ 12.7$ & 1.03 \\
\hline PTC/ITC Extension & 306 & 0.127 & 6,719 & $\$ 78.5$ & $\$ 14.0$ & 5.59 \\
\hline State CES & 698 & 0.289 & 19 & $\$ 91.2$ & $\$ 125.7$ & 0.73 \\
\hline PTC/ITC Extension and State CES & 287 & 0.119 & 6,879 & $\$ 76.9$ & $\$ 13.4$ & 5.75 \\
\hline $100 \%$ Hybrid CES (\$40 ACP) +Extension & 197 & 0.082 & 7,172 & $\$ 75.8$ & $\$ 14.8$ & 5.13 \\
\hline \multicolumn{7}{|l|}{ High renewables/high gas price scenario } \\
\hline BAU & 1,640 & 0.679 & - & - & & - \\
\hline$\$ 20$ Carbon Tax & 800 & 0.331 & 13,879 & $\$ 16.8$ & $\$ 17.2$ & 0.98 \\
\hline$\$ 40$ Carbon Tax & 336 & 0.139 & 20,587 & $\$ 24.3$ & $\$ 24.4$ & 0.99 \\
\hline TPS & 361 & 0.149 & 14,500 & $\$ 22.5$ & $\$ 23.4$ & 0.96 \\
\hline $90 \% \mathrm{CES}$ & 587 & 0.243 & 7,779 & $\$ 33.4$ & $\$ 20.5$ & 1.63 \\
\hline $100 \%$ Hybrid CES, \$20 ACP & 721 & 0.298 & 7,729 & $\$ 20.6$ & $\$ 17.4$ & 1.18 \\
\hline $100 \%$ Hybrid CES, $\$ 40$ ACP & 276 & 0.114 & 10,659 & $\$ 29.6$ & $\$ 24.4$ & 1.22 \\
\hline PTC/ITC Extension & 1,351 & 0.559 & 2,354 & $\$ 66.8$ & $\$ 15.3$ & 4.37 \\
\hline State CES & 1,638 & 0.678 & 103 & $\$ 63.4$ & $\$ 60.3$ & 1.05 \\
\hline PTC/ITC Extension and State CES & 1,317 & 0.545 & 2,618 & $\$ 61.9$ & $\$ 15.6$ & 3.97 \\
\hline $100 \%$ Hybrid CES $(\$ 40 \mathrm{ACP})+$ Extension & 158 & 0.065 & 10,891 & $\$ 55.6$ & $\$ 29.4$ & 1.89 \\
\hline
\end{tabular}

Notes: See the notes to Table 2. 
Figure 3. Changes in Average Annual Generation, By Scenario

(a) Low demand, reference prices

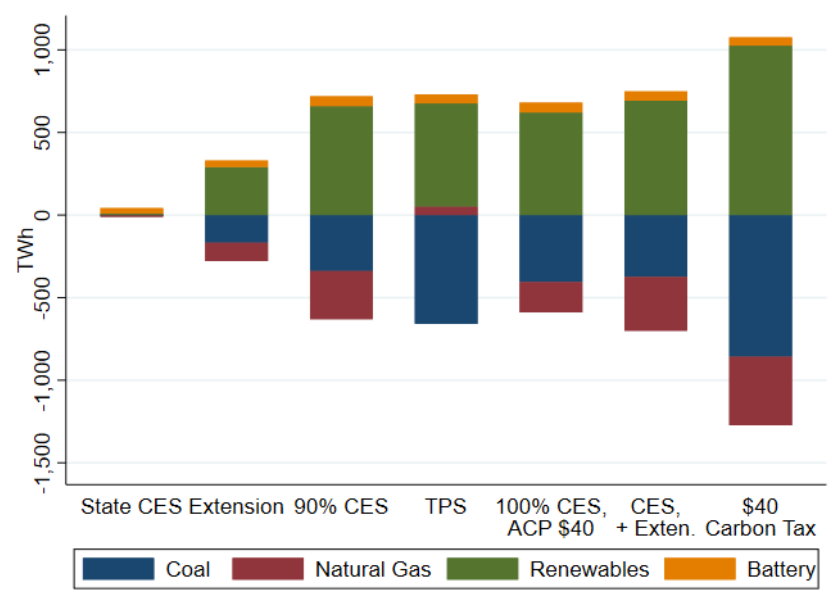

(b) High demand, high natural gas price, low renewables price

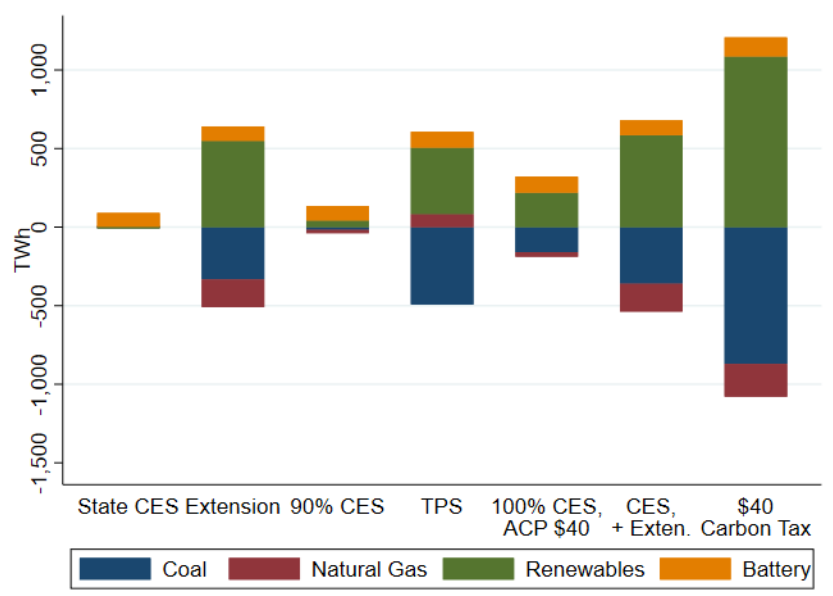

(c) High demand, low natural gas price, high renewables price

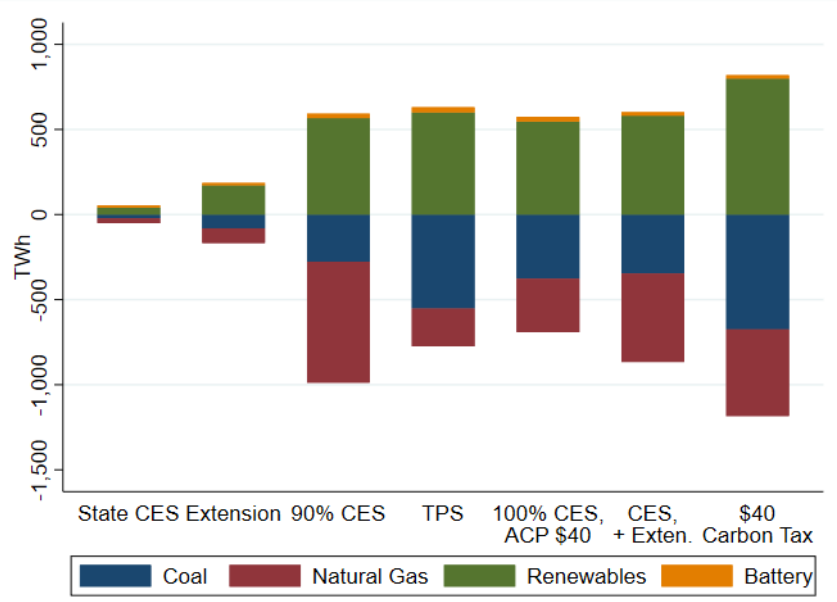


The hybrid 100\% CES with \$40 ACP achieves emissions reductions of 83\%-95\%. When the hybrid $100 \%$ CES with $\$ 40$ ACP achieves the same abatement as the TPS, the two policies have per-ton abatement costs that are quite close. When their abatement differs, the policy with greater emissions reductions has the higher abatement cost. For example, in the low demand, low renewables price, low gas price case - a scenario in which low gas prices largely drive out coal without policy - the TPS achieves $85 \%$ abatement at a cost of $\$ 19 /$ ton, whereas the $100 \%$ CES with $\$ 40$ ACP achieves $94 \%$ abatement at a cost of $\$ 30 /$ ton. In this scenario, the low price of coal and renewables enable achieving very high renewables before the clean energy credit price hits the ACP cap. The partial crediting of gas in the hybrid 100\% CES with \$40 ACP essentially drives out coal generation under all price scenarios.

The TPS and the hybrid 100\% CES with $\$ 40$ ACP have different timings of stringency and thus emissions reductions. The TPS, as modeled here, is more stringent than the hybrid CES in the 2020s, so its initially greater emissions reductions translate into greater cumulative reductions. This timing difference is a consequence of the modeled ramp-in period. Both policies are costeffective, having prices per ton abated within $10 \%$ of the price per ton of the emissionsequivalent cap-and-trade system.

The carbon tax (either $\$ 40$ or $\$ 20$ ), the 90\% CES, and the hybrid 100\% CES with $\$ 20$ ACP fail to drive emissions reductions of at least $80 \%$ in some scenarios. Under the low natural gas/high renewable price scenario, the $\$ 20$ carbon price is insufficient to replace gas generation with renewables; for the same reason, the $\$ 20 \mathrm{ACP}$ in the hybrid CES is too low as a cap on the clean energy credit price. Although the $\$ 40$ carbon tax drives deep reductions under reference prices with both low and high demand, when gas is inexpensive and renewables are expensive the $\$ 40$ carbon price results in only $78 \%-79 \%$ emissions reduction. ${ }^{15}$

The performance of the $90 \%$ CES depends on economic conditions. In the low renewables price/high gas price scenarios, the price of clean energy credits is relatively low (because renewables are inexpensive). Because there is no partial crediting for gas, when gas prices are high, the allowed fossil percentage skews towards coal, driving up emissions. As a result, the effect of the $90 \%$ CES on emissions depends strongly on the price of natural gas. ${ }^{16}$ There is a

\footnotetext{
${ }^{15}$ EIA AEO (2020) considers a $\$ 35$ carbon tax side case, which results in $82 \%$ emissions reductions in 2035 , relative to 2005, and 10,060 mmton cumulative emissions reductions 2020-2035, relative to the EIA reference case. These reductions are less than those for the slightly higher $\$ 40 /$ ton carbon tax in Table 2, which under the reference case have $87 \%$ emissions reductions by 2035 and cumulative reductions of 16,020. One reason for the discrepancy is the timing of the closing of coal generation, which occurs more quickly under the $\$ 40$ carbon tax in ReEDS than under the $\$ 35$ carbon tax in the EIA side case.

${ }^{16}$ This dependence of emissions reductions on the price of gas does not appear in Phadke et al. (2020) because under all CES scenarios they assume that all coal plants are exogenously retired in a linear manner from 2020 to 2035; thus, by 2035, the only emissions are (mechanically) from gas generation. If gas prices are high, however, coal remains economic and ReEDS retains coal capacity and dispatches coal when it is economically efficient to do so.
} 
small interaction with the price of renewables: when renewables are expensive, the clean energy credit price increases, but because there is no partial crediting, the implied cost per ton of emissions for coal is less than for gas, again skewing towards coal. Even with $90 \%$ of generation being clean by 2035 , the remaining $10 \%$ can be heavily oriented towards coal that is used for marginal capacity (Figure 3 ). The $90 \%$ CES is $8 \%$ - 47\% more costly per ton abated, depending on the price scenario, than the emissions-equivalent cap-and-trade. This reflects the fact that the CES is equivalent to a subsidy to clean generation and a tax on fossil fuel generation, but the implicit carbon tax is less for coal than gas.

As can be seen in Figure 2, wholesale prices under the TPS and hybrid CES with \$40 ACP are similar, with the TPS price slightly higher in the middle of the simulation as a result of its earlier stringency. Under the low renewables/high gas price scenario, wholesale prices increase by $\$ 0$ \$4.3/MWh under the TPS from 2020 to 2035 and by $-\$ 0.07-\$ 2.7 / \mathrm{MWh}$ under the hybrid $100 \%$ CES with $\$ 40$ ACP.

ITC/PTC extension. The ITC/PTC extension fails to drive robust significant emissions reductions. In the reference technology scenarios, the ITC/PTC extension reduces emissions by $62 \%$ - 64\%. Although the ITC and the PTC reduce the cost of building renewables, they do not change the marginal cost of fossil fuel generation, limiting the emissions reductions arising from the tax credit extension. ${ }^{17}$ When in the high renewables/high gas price scenarios, the tax credit extension is ineffective because construction of new renewables is retarded by their high price, which is only partially offset by the tax credit extension, and the high price of gas leads to a large amount of coal generation, leading to emissions reductions of only 43\%-44\% relative to 2005 .

Because of declining renewables costs, a substantial amount of wind and solar is projected to be built under BAU, even without the ITC and PTC. Thus, if the ITC and PTC are extended, a substantial amount of spending on the ITC and PTC would be inframarginal, going to renewable capacity that would have been built in any event. As a result, the ITC and PTC are not costeffective abatement policies in the sense that their cost-per-ton is 7-8 times than under the equivalent cap-and-trade program in the reference case. Extending the tax credits slightly reduces wholesale electricity prices, relative to BAU, because the tax credits are a net subsidy to the power sector which are passed through to wholesale markets.

\footnotetext{
17 These results suggest a greater effect on emissions of the PTC/ITC extension than the other ITC/PTC extension simulation we are aware of, in EIA AEO (2018), which considered a side case in which the ITC and PTC were extended at current levels through 2050. That simulation estimates that power sector emissions are essentially unchanged in 2020, however the time profile of emissions changes: with ITC/PTC expiration, under the perfect foresight assumptions of the model there is more renewables construction in the early 2020s so emissions initially are higher if the ITC/PTC are extended, but starting mid-2030s the ITC/PTC extension spurs additional renewables construction. Even by 2050, however, EIA (2018) estimates the effect of the ITC/PTC extension to be small, reducing emissions, relative to 2005 , by only 6 percentage points, relative to the reference case.
} 
Hybrid CES + ITC/PTC extension. The hybrid 100\% CES with \$40 ACP in combination with the tax credit extension drives the deepest robust emissions reductions, estimated to be between $91 \%$ and $95 \%$ across the ten scenarios. The reason is that the tax credit extension is complementary to the hybrid CES in the cases in which the hybrid CES is relatively less effective. For example, the hybrid CES drives the least reductions (83\%) in the high demand, high renewables/low gas price scenario: with the high renewables price, the clean energy credit hits the ACP price cap by the mid-2030s, limiting additional renewables construction (Figure 3(c)). The ITC/PTC extension lowers the cost of wind and solar to the private sector, countering the otherwise-high renewables prices and allowing additional renewables construction. The stillhigh clean energy credit, with partial crediting for gas, builds on the low cost of gas to reduce coal generation further as new renewables come online. The ITC/PTC subsidy for renewables has less marginal impact under the reference price scenarios, and under the low renewables price scenarios, the ITC/PTC subsidy is almost entirely inframarginal. In fact, in the high demand, low renewables, high gas price scenario, emissions are slightly higher under the hybrid CES with the tax credit extension than without. In this case, the tax credit extension reduces the clean energy credit price enough to give coal a competitive edge so that more coal is used with the tax credit than without, however this effect is small and in this scenario emissions reductions are $91.8 \%$ with the tax credit and $92.3 \%$ without it.

Because the ITC/PTC extension provides a net flow of funds into the power system, which are passed through to the wholesale price, wholesale prices are lower under the hybrid $100 \% \mathrm{CES}$ with \$40 ACP with the tax credit extension than without the extension. We examine this price impact regionally in Section 6.

State CES. In all technology price scenarios, the marginal contribution of enhanced state CES to national emissions reductions is negligible, for three reasons. First, the additional emissions covered by this expansion are a fairly small share of national emissions. Second, for states already in the Regional Greenhouse Gas Initiative (RGGI), additional reductions within those three states allows emissions in the other RGGI states to rise to the RGGI cap. Third, for the nonRGGI states, reducing in-state emissions can have leakage because all the states are part of a reginal dispatch system, so fossil fuel generation that would have been dispatched in a CES state is replaced in part by dispatching fossil fuel in a connected state.

The efficiency analysis in Table 2 and Table 3 indicates that enhanced state ambition is far less efficient than an emissions-equivalent cap-and-trade system (note however that in some scenarios the emissions reductions under the state CES are so small that the equivalent C\&T path is in the range of model numerical error for the step size we use). That said, while it yields few tons of abatement, the average cost of this policy is in the range of $\$ 25-\$ 91$, less than Greenstone and Nath's (2020) estimate of the RPS costs exceeding \$100 estimated. However, 
Greenstone and Nath (2020) looked at historical evidence, when wind and solar were significantly more expensive than they are now and are projected to be in the simulations.

Comparison to $S \boldsymbol{C C}$. The results here provide qualified evidence on the cost-benefit ratio of the policies. There are two main qualifications, both of which suggest that comparing the SCC to the per-ton costs understates the benefit-cost ratio. First, reducing coal generation has significant health co-benefits, which are not included in the SCC. Second, the costs and emissions reductions are computed only over the period 2022-2036. The costs are annuitized so a 20-year wind farm entering production in, say, 2030, has the first 7 years of its annuitized costs included in the 2022-2036 window, and the first 7 years of its emissions benefits are included in the window. Using these annuitized costs and emissions over the truncated window approximates the full costs and emissions but misses some subtleties such as the growth of the SCC for laterdated emissions. In addition, comparing costs and benefits over this window excludes any dynamic benefits from learning by doing, for example see Nemet (2019) for photovoltaics or Gillingham and Stock (2018) for a general discussion.

With these caveats, the two policies that individually result in deep decarbonization - the TPS and the hybrid $100 \% \mathrm{CES}$ with $\$ 40 \mathrm{ACP}$ - both have per-ton costs less than (often much less than) the current US Government estimate of the SCC, $\$ 51 /$ ton $\mathrm{CO}_{2}$, across all the scenarios. Thus, these policies provide robust deep decarbonization, are cost-effective, and have positive net climate benefits. The combination policy of the hybrid $100 \%$ CES ( $\$ 40$ ACP) and the tax credit extension has per-ton cost near or less than the SCC in 5 of the 10 scenarios, however its highest cost-per-ton (\$93 in the high demand, low renewables, low gas price scenario) substantially exceeds the current US Government SCC.

\subsection{Fiscal Impacts}

The fiscal impacts of these policies are summarized in Table 4 for the low demand scenarios and in Table 5 for the high demand scenarios. The fiscal impacts arise from the existing PTC and ITC and from some of the policies through the extension of the tax credits, receipt of carbon taxes, and receipt of alternative compliance payments in the hybrid CESs. We annuitize the net present value of the federal expenditures using a 5\% discount rate and a 20-year time horizon. The 20-year time horizon reflects the assumed operating lifetime of capital investments in ReEDs and thus the stream of expenditures associated with the production tax credit for qualifying technologies. Although the investment tax credit is claimed on the year the qualifying technology is placed in service, there is a safe harbor provision that allows the ITC to be claimed within four calendar years of the start of construction. As a result, PTC and ITC federal tax expenditures will be incurred for a number of years after the expiration of the credits. 
Looking across all scenarios, the hybrid 100\% CES ( $\$ 40 \mathrm{ACP}$ ) incurs less than $\$ 1 \mathrm{~B}$ in additional annual federal expenditures, and the TPS incurs $\$ 2-4 \mathrm{~B}$ additional federal expenditures. The reason the fiscal cost of the TPS is higher than for the hybrid CES is that the TPS is more stringent earlier, spurring additional renewables construction while the tax credits are still available.

Extending the ITC and PTC alone results in between \$3B and \$28B of additional federal expenditures annually, with the greatest costs arising when renewables are inexpensive and demand is high (so that more renewables are built).

Augmenting the hybrid 100\% CES ( $\$ 40 \mathrm{ACP}$ ) with the tax credit extension increases federal expenditures by $\$ 16 \mathrm{~B}$ annually under the reference technology scenario, and by $\$ 10 \mathrm{~B}-\$ 29 \mathrm{~B}$ annually looking across all scenarios.

Relative to BAU, the carbon tax policies generate additional revenues on the order of $\$ 20 \mathrm{~B} / \mathrm{year}$ under the reference price scenario. An interesting feature is that, under the carbon tax in the reference scenario, receipts only increase by $20 \%-22 \%$ for a doubling of the tax rate from $\$ 20$ to $\$ 40$, indicating the high elasticity of emissions with respect to the tax rate. 
Table 4. Annuitized Federal Net Revenues: Low Demand

\begin{tabular}{|c|c|c|c|c|c|}
\hline Climate Policy & $\begin{array}{c}\text { Expenditures: } \\
\text { ITC } \\
\end{array}$ & $\begin{array}{c}\text { Expenditures: } \\
\text { PTC } \\
\end{array}$ & Receipts & $\begin{array}{c}\text { Net } \\
\text { Revenues }\end{array}$ & $\begin{array}{c}\text { Net Revenues } \\
\text { minus BAU }\end{array}$ \\
\hline \multicolumn{6}{|l|}{ Reference Technology Scenario: } \\
\hline BAU & -2.8 & -4.8 & 0.0 & -7.6 & \\
\hline$\$ 20$ Carbon Tax & -5.4 & -7.9 & 16.5 & 3.2 & 10.8 \\
\hline$\$ 40$ Carbon Tax & -7.2 & -10.0 & 20.2 & 3.0 & 10.5 \\
\hline TPS & -5.1 & -5.7 & 0.0 & -10.8 & -3.3 \\
\hline $90 \% \mathrm{CES}$ & -4.3 & -4.8 & 0.0 & -9.1 & -1.5 \\
\hline $100 \%$ Hybrid CES, \$20 ACP & -3.8 & -4.8 & 1.1 & -7.5 & 0.0 \\
\hline 100\% Hybrid CES, \$40 ACP & -4.1 & -4.8 & 0.5 & -8.4 & -0.8 \\
\hline PTC/ITC Extension & -5.2 & -10.9 & 0.0 & -16.1 & -8.5 \\
\hline State CES & -2.9 & -4.8 & 0.0 & -7.7 & -0.2 \\
\hline PTC/ITC Extension and State CES & -5.4 & -10.8 & 0.0 & -16.2 & -8.7 \\
\hline $100 \%$ Hybrid CES ( $\$ 40$ ACP) + Extension & -7.7 & -16.4 & 0.1 & -24.0 & -16.4 \\
\hline \multicolumn{6}{|l|}{ Low renewables/low gas price scenario } \\
\hline BAU & -2.8 & -4.8 & 0.0 & -7.6 & \\
\hline$\$ 20$ Carbon Tax & -4.6 & -8.4 & 15.5 & 2.5 & 10.1 \\
\hline$\$ 40$ Carbon Tax & -6.2 & -10.5 & 17.4 & 0.8 & 8.4 \\
\hline TPS & -4.0 & -5.8 & 0.0 & -9.7 & -2.2 \\
\hline $90 \% \mathrm{CES}$ & -3.7 & -4.8 & 0.0 & -8.5 & -0.9 \\
\hline $100 \%$ Hybrid CES, \$20 ACP & -3.3 & -4.8 & 0.8 & -7.3 & 0.3 \\
\hline $100 \%$ Hybrid CES, \$40 ACP & -3.5 & -4.8 & 0.0 & -8.3 & -0.8 \\
\hline PTC/ITC Extension & -4.2 & -20.8 & 0.0 & -25.0 & -17.4 \\
\hline State CES & -2.8 & -4.9 & 0.0 & -7.7 & -0.1 \\
\hline PTC/ITC Extension and State CES & -4.4 & -20.1 & 0.0 & -24.5 & -17.0 \\
\hline 100\% Hybrid CES ( $\$ 40 \mathrm{ACP})+$ Extension & -5.7 & -25.1 & 0.0 & -30.8 & -23.2 \\
\hline \multicolumn{6}{|l|}{ High renewables/low gas price scenario } \\
\hline BAU & -2.4 & -4.8 & 0.0 & -7.1 & \\
\hline$\$ 20$ Carbon Tax & -3.8 & -6.6 & 22.3 & 11.9 & 19.0 \\
\hline$\$ 40$ Carbon Tax & -5.8 & -8.5 & 28.8 & 14.6 & 21.7 \\
\hline TPS & -4.2 & -5.2 & 0.0 & -9.3 & -2.2 \\
\hline $90 \% \mathrm{CES}$ & -3.9 & -4.8 & 0.0 & -8.6 & -1.5 \\
\hline 100\% Hybrid CES, \$20 ACP & -3.2 & -4.8 & 2.6 & -5.4 & 1.7 \\
\hline $100 \%$ Hybrid CES, $\$ 40$ ACP & -3.9 & -4.8 & 0.8 & -7.9 & -0.8 \\
\hline PTC/ITC Extension & -4.0 & -6.0 & 0.0 & -10.1 & -2.9 \\
\hline State CES & -2.6 & -4.8 & 0.0 & -7.4 & -0.3 \\
\hline PTC/ITC Extension and State CES & -4.4 & -6.5 & 0.0 & -10.9 & -3.8 \\
\hline $100 \%$ Hybrid CES $(\$ 40 \mathrm{ACP})+$ Extension & -6.5 & -11.2 & 0.3 & -17.3 & -10.2 \\
\hline
\end{tabular}


Table 4, continued

\begin{tabular}{|c|c|c|c|c|c|}
\hline Climate Policy & $\begin{array}{l}\text { Expenditures: } \\
\text { ITC }\end{array}$ & $\begin{array}{l}\text { Expenditures: } \\
\text { PTC }\end{array}$ & Receipts & $\begin{array}{c}\text { Net } \\
\text { Revenues }\end{array}$ & $\begin{array}{c}\text { Net Revenues } \\
\text { minus BAU }\end{array}$ \\
\hline \multicolumn{6}{|l|}{ Low renewables/high gas price scenario } \\
\hline$\overline{\mathrm{BAU}}$ & -3.4 & -5.2 & 0.0 & -8.6 & \\
\hline \$20 Carbon Tax & -7.0 & -10.7 & 7.8 & -9.9 & -1.3 \\
\hline$\$ 40$ Carbon Tax & -8.4 & -12.4 & 8.9 & -11.9 & -3.4 \\
\hline TPS & -5.2 & -7.1 & 0.0 & -12.3 & -3.7 \\
\hline $90 \% \mathrm{CES}$ & -3.6 & -5.2 & 0.0 & -8.8 & -0.2 \\
\hline $100 \%$ Hybrid CES, \$20 ACP & -3.9 & -5.2 & 0.0 & -9.1 & -0.5 \\
\hline $100 \%$ Hybrid CES, \$40 ACP & -3.9 & -5.2 & 0.0 & -9.1 & -0.5 \\
\hline PTC/ITC Extension & -5.8 & -26.7 & 0.0 & -32.4 & -23.9 \\
\hline State CES & -3.4 & -5.2 & 0.0 & -8.7 & -0.1 \\
\hline PTC/ITC Extension and State CES & -5.8 & -26.3 & 0.0 & -32.1 & -23.5 \\
\hline $100 \%$ Hybrid CES $(\$ 40$ ACP $)+$ Extension & -6.3 & -27.9 & 0.0 & -34.1 & -25.6 \\
\hline \multicolumn{6}{|l|}{ High renewables/high gas price scenario } \\
\hline$\overline{\mathrm{BAU}}$ & -3.1 & -4.8 & 0.0 & -7.9 & \\
\hline \$20 Carbon Tax & -6.1 & -8.5 & 21.4 & 6.8 & 14.7 \\
\hline$\$ 40$ Carbon Tax & -8.2 & -10.8 & 20.6 & 1.7 & 9.6 \\
\hline TPS & -5.9 & -6.4 & 0.0 & -12.3 & -4.4 \\
\hline $90 \% \mathrm{CES}$ & -4.8 & -4.8 & 0.0 & -9.6 & -1.7 \\
\hline $100 \%$ Hybrid CES, \$20 ACP & -4.0 & -4.8 & 2.8 & -6.0 & 1.9 \\
\hline $100 \%$ Hybrid CES, $\$ 40$ ACP & -4.8 & -4.8 & 0.5 & -9.1 & -1.2 \\
\hline PTC/ITC Extension & -5.8 & -10.0 & 0.0 & -15.7 & -7.8 \\
\hline State CES & -3.2 & -4.8 & 0.0 & -8.1 & -0.2 \\
\hline PTC/ITC Extension and State CES & -5.9 & -10.1 & 0.0 & -16.0 & -8.1 \\
\hline $100 \%$ Hybrid CES $(\$ 40$ ACP $)+$ Extension & -9.6 & -16.8 & 0.1 & -26.3 & -18.4 \\
\hline
\end{tabular}

Notes: Federal revenues and expenditures are expressed in billions of $2018 \$$ and are annuitized assuming a $5 \%$ discount rate and 20 year time horizon. 
Table 5. Annuitized Federal Net Revenues: High Demand

\begin{tabular}{|c|c|c|c|c|c|}
\hline Climate Policy & $\begin{array}{c}\text { Expenditures: } \\
\text { ITC } \\
\end{array}$ & $\begin{array}{l}\text { Expenditures: } \\
\text { PTC } \\
\end{array}$ & Receipts & $\begin{array}{c}\text { Net } \\
\text { Revenues }\end{array}$ & $\begin{array}{c}\text { Net Revenues } \\
\text { minus BAU }\end{array}$ \\
\hline \multicolumn{6}{|l|}{ Reference Technology Scenario: } \\
\hline BAU & -3.6 & -4.8 & 0.0 & -8.4 & \\
\hline$\$ 20$ Carbon Tax & -6.5 & -8.0 & 16.8 & 2.3 & 10.7 \\
\hline$\$ 40$ Carbon Tax & -8.1 & -10.2 & 20.2 & 1.9 & 10.3 \\
\hline TPS & -5.7 & -5.8 & 0.0 & -11.6 & -3.2 \\
\hline $90 \% \mathrm{CES}$ & -4.8 & -4.8 & 0.0 & -9.6 & -1.2 \\
\hline $100 \%$ Hybrid CES, \$20 ACP & -4.5 & -4.8 & 0.9 & -8.4 & 0.0 \\
\hline $100 \%$ Hybrid CES, $\$ 40$ ACP & -4.7 & -4.8 & 0.3 & -9.3 & -0.9 \\
\hline PTC/ITC Extension & -7.1 & -12.6 & 0.0 & -19.7 & -11.3 \\
\hline State CES & -3.7 & -4.9 & 0.0 & -8.5 & -0.1 \\
\hline PTC/ITC Extension and State CES & -7.2 & -13.0 & 0.0 & -20.1 & -11.7 \\
\hline $100 \%$ Hybrid CES ( $\$ 40$ ACP) + Extension & -10.0 & -19.0 & 0.0 & -29.0 & -20.6 \\
\hline \multicolumn{6}{|l|}{$\underline{\text { Low renewables/low gas price scenario }}$} \\
\hline BAU & -3.3 & -4.8 & 0.0 & -8.2 & \\
\hline \$20 Carbon Tax & -5.3 & -8.6 & 15.6 & 1.8 & 10.0 \\
\hline$\$ 40$ Carbon Tax & -6.8 & -10.7 & 16.5 & -1.0 & 7.1 \\
\hline TPS & -4.5 & -5.8 & 0.0 & -10.3 & -2.1 \\
\hline $90 \%$ CES & -4.0 & -4.8 & 0.0 & -8.9 & -0.7 \\
\hline $100 \%$ Hybrid CES, \$20 ACP & -3.8 & -4.8 & 0.5 & -8.1 & 0.0 \\
\hline $100 \%$ Hybrid CES, $\$ 40$ ACP & -3.9 & -4.8 & 0.0 & -8.8 & -0.6 \\
\hline PTC/ITC Extension & -5.5 & -23.4 & 0.0 & -28.9 & -20.7 \\
\hline State CES & -3.4 & -4.9 & 0.0 & -8.3 & -0.1 \\
\hline PTC/ITC Extension and State CES & -5.6 & -23.0 & 0.0 & -28.6 & -20.4 \\
\hline 100\% Hybrid CES ( $\$ 40$ ACP) + Extension & -6.7 & -28.4 & 0.0 & -35.1 & -26.9 \\
\hline \multicolumn{6}{|l|}{ High renewables/low gas price scenario } \\
\hline BAU & -3.0 & -4.8 & 0.0 & -7.8 & \\
\hline \$20 Carbon Tax & -4.7 & -6.7 & 24.0 & 12.6 & 20.4 \\
\hline$\$ 40$ Carbon Tax & -6.7 & -8.6 & 30.0 & 14.7 & 22.5 \\
\hline TPS & -5.1 & -5.2 & 0.0 & -10.3 & -2.5 \\
\hline $90 \% \mathrm{CES}$ & -4.5 & -4.8 & 0.0 & -9.2 & -1.4 \\
\hline $100 \%$ Hybrid CES, \$20 ACP & -4.1 & -4.8 & 2.7 & -6.2 & 1.5 \\
\hline $100 \%$ Hybrid CES, $\$ 40$ ACP & -4.7 & -4.8 & 0.9 & -8.5 & -0.7 \\
\hline PTC/ITC Extension & -6.1 & -7.7 & 0.0 & -13.8 & -6.0 \\
\hline State CES & -3.2 & -4.8 & 0.0 & -8.0 & -0.2 \\
\hline PTC/ITC Extension and State CES & -6.4 & -7.8 & 0.0 & -14.2 & -6.4 \\
\hline $100 \%$ Hybrid CES $(\$ 40 \mathrm{ACP})+$ Extension & -8.4 & -13.2 & 0.3 & -21.3 & -13.5 \\
\hline
\end{tabular}


Table 5, continued

\begin{tabular}{|c|c|c|c|c|c|}
\hline Climate Policy & $\begin{array}{l}\text { Expenditures: } \\
\text { ITC } \\
\end{array}$ & $\begin{array}{c}\text { Expenditures: } \\
\text { PTC } \\
\end{array}$ & Receipts & $\begin{array}{c}\text { Net } \\
\text { Revenues }\end{array}$ & $\begin{array}{c}\text { Net Revenues } \\
\text { minus BAU }\end{array}$ \\
\hline \multicolumn{6}{|l|}{ Low renewables/high gas price scenario } \\
\hline BAU & -4.0 & -5.2 & 0.0 & -9.2 & \\
\hline$\$ 20$ Carbon Tax & -7.6 & -10.8 & 7.8 & -10.7 & -1.4 \\
\hline$\$ 40$ Carbon Tax & -8.9 & -12.6 & 9.0 & -12.5 & -3.2 \\
\hline TPS & -5.7 & -7.3 & 0.0 & -12.9 & -3.7 \\
\hline $90 \% \mathrm{CES}$ & -4.1 & -5.2 & 0.0 & -9.4 & -0.1 \\
\hline 100\% Hybrid CES, \$20 ACP & -4.3 & -5.2 & 0.0 & -9.6 & -0.4 \\
\hline 100\% Hybrid CES, \$40 ACP & -4.4 & -5.2 & 0.0 & -9.6 & -0.4 \\
\hline PTC/ITC Extension & -7.4 & -29.9 & 0.0 & -37.3 & -28.1 \\
\hline State CES & -4.0 & -5.3 & 0.0 & -9.3 & -0.1 \\
\hline PTC/ITC Extension and State CES & -7.5 & -29.9 & 0.0 & -37.4 & -28.2 \\
\hline 100\% Hybrid CES ( $\$ 40$ ACP) + Extension & -7.7 & -30.6 & 0.0 & -38.2 & -29.0 \\
\hline \multicolumn{6}{|l|}{ High renewables/high gas price scenario } \\
\hline BAU & -4.1 & -4.8 & 0.0 & -8.9 & \\
\hline \$20 Carbon Tax & -7.4 & -8.6 & 22.5 & 6.5 & 15.4 \\
\hline$\$ 40$ Carbon Tax & -9.4 & -10.9 & 20.9 & 0.6 & 9.5 \\
\hline TPS & -6.8 & -6.4 & 0.0 & -13.2 & -4.4 \\
\hline $90 \%$ CES & -5.5 & -4.8 & 0.0 & -10.3 & -1.4 \\
\hline 100\% Hybrid CES, \$20 ACP & -5.1 & -4.8 & 2.1 & -7.8 & 1.1 \\
\hline 100\% Hybrid CES, \$40 ACP & -5.7 & -4.8 & 0.4 & -10.1 & -1.2 \\
\hline PTC/ITC Extension & -8.4 & -12.5 & 0.0 & -20.9 & -12.0 \\
\hline State CES & -4.2 & -4.8 & 0.0 & -9.0 & -0.1 \\
\hline PTC/ITC Extension and State CES & -8.7 & -12.6 & 0.0 & -21.2 & -12.3 \\
\hline $100 \%$ Hybrid CES $(\$ 40$ ACP $)+$ Extension & -12.1 & -19.7 & 0.1 & -31.8 & -22.9 \\
\hline
\end{tabular}

Notes: Federal revenues and expenditures are expressed in billions of $2018 \$$ and are annuitized assuming a 5\% discount rate and 20 year time horizon. 


\section{Regional Price Impacts}

We now turn to state-level impacts of several of these policies on wholesale electricity prices. All results in this section are for the reference technology and electrification scenario.

States differ in their current coal and gas shares of generation and also in their renewable resources. At a high level, generators (or obligated load-serving entities) in states with high renewable resources will be able to sell clean energy credits to states with high fossil shares and/or low renewable resources. As a result, the price effects of the policies differ across states and those patterns also differ across policies.

Figure 4 and Figure 5 show the average annual 2022-2035 difference in state electricity prices, relative to BAU, under the TPS and the hybrid 100\% CES ( $\$ 40$ ACP). For both policies, price increases are largest in states with the highest current coal and natural gas shares and with low renewable resources (Midwest and some Southern states). Under the TPS, price increases range from $\$ 1.12 / \mathrm{MWh}$ (New Hampshire) to $\$ 4.30$ (Missouri). For a household that consumes the 2019 annual average of $10.649 \mathrm{MWh},{ }^{18}$ this amounts to $\$ 12$ to $\$ 46$ per year of additional electricity charges. ${ }^{19}$ Price increases for the hybrid CES range from $\$ 0.87 / \mathrm{MWh}$ (California) to $\$ 4.51$ (West Virginia). The ACP generates modest revenues. In principle, the revenues under the hybrid 100\% CES with \$40 ACP could be rebated lump-sum to customers. If the rebates were calculated so that the electricity price increase was the same in each state, the increase would be $\$ 2.10 / \mathrm{MWh}^{20}$

Figure 6 shows state price changes under the combined hybrid 100\% CES with $\$ 40$ ACP and tax credit extension. Because of the tax credit extension, prices are close to those under the BAU scenario. States with ambitious clean energy standards like New York and California experience small price decreases because the tax credit extension lowers the cost of meeting the state standard. States in the Midwest experience modest price increases of \$0.98/MWh on average, which is lower than the average $\$ 3.63 / \mathrm{MWh}$ increase in prices for these states under the hybrid $100 \%$ CES with $\$ 40$ ACP.

The pattern of price increases in the 90\% CES (Figure 7) is generally similar, although they are less for the upper Midwest which has both high wind resources and currently high coal usage, than under the TPS. Because gas does not get partial crediting, the penalty for using coal under the $90 \%$ CES is less than under the TPS or the hybrid CES, which (as discussed above) leads to

\footnotetext{
${ }^{18} \mathrm{EIA}$ at https://www.eia.gov/tools/faqs/faq.php?id=97\&t=3

${ }^{19}$ These estimates only reflect changes in wholesale electricity prices and do not include any changes in transmission or distribution costs that may be passed onto retail customers under high decarbonization scenarios. ${ }^{20}$ This calculation assumes that states with a pre-transfer price increase below the average net increase in prices receive zero transfers.
} 
more coal use (and higher emissions). The continued use of coal in the upper Midwest slightly reduces the cost of the $90 \%$ CES.

The policy with the greatest cumulative emissions reductions is the $\$ 40$ carbon tax; it also has the highest price increases. We consider lump-sum per-capita rebating of the carbon tax. To keep units comparable, we convert this lump-sum payment to the units of electricity prices by dividing by average electricity consumption in the state; this approximates the net burden to average ratepayers although it does not show the actual price they pay. Figure 8 shows price increases net of this per-capita dividend payment of the power-sector receipts from the $\$ 40$ carbon tax. After the rebate, price increases range from $\$ 0.68$ (New York) to $\$ 7.84 / \mathrm{MWh}$ (West Virginia), which correspond to $\$ 7.24$ to $\$ 83.49 /$ year for a typical household.

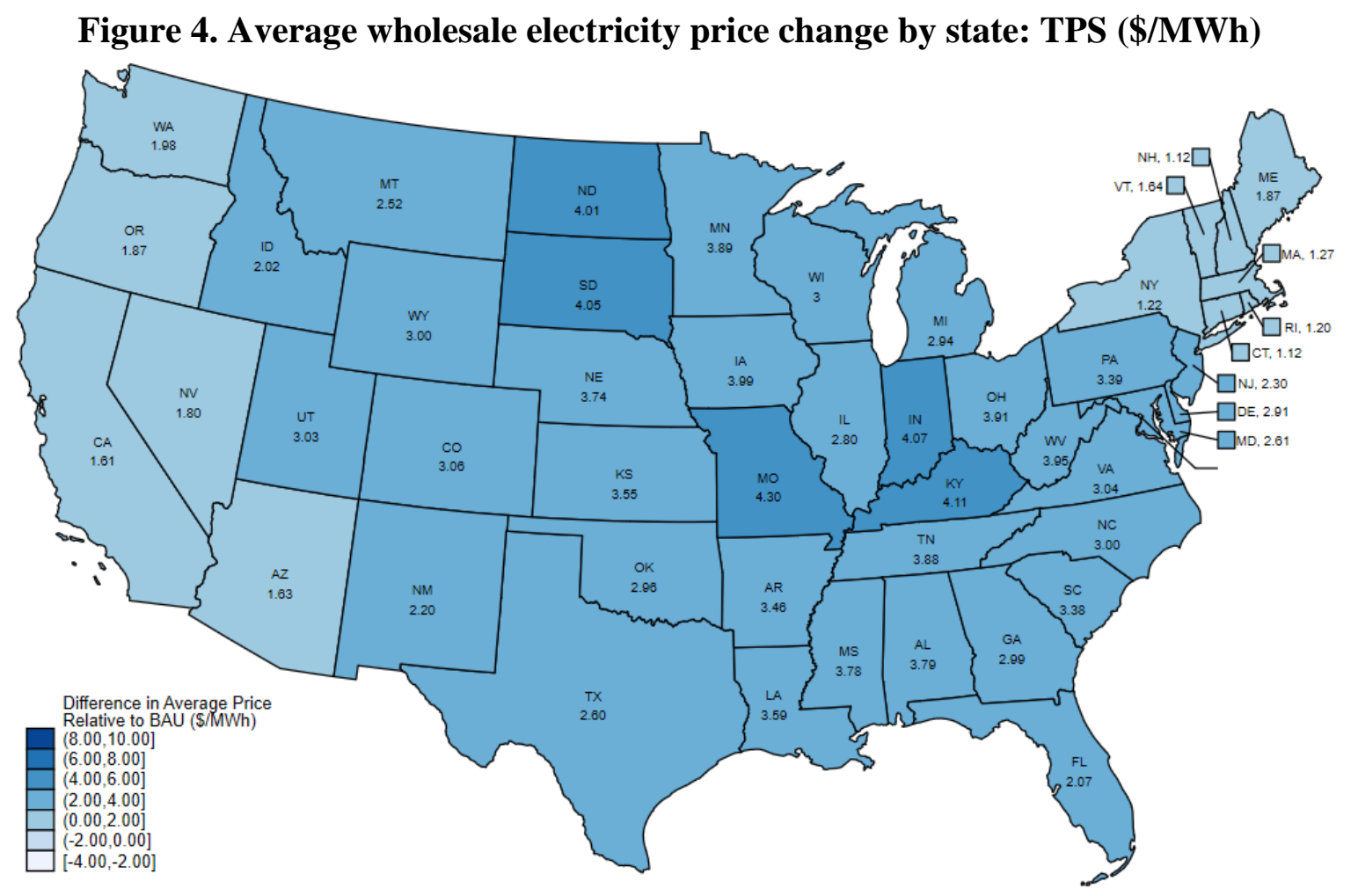


Figure 5. Average wholesale electricity price change by state: Hybrid $100 \%$ CES with $\$ 40$ $\mathrm{ACP}(\$ / \mathrm{MWh})$

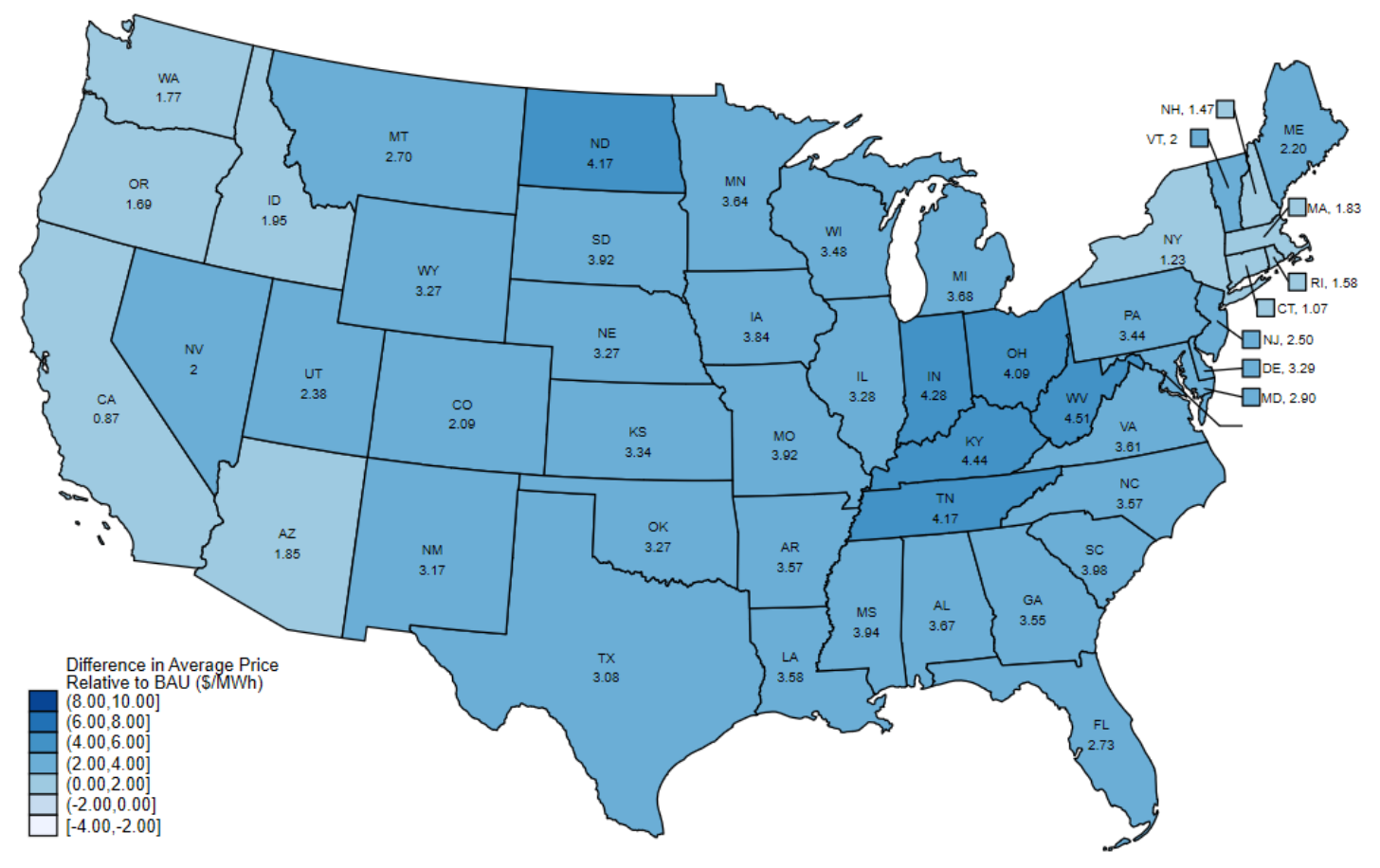

Figure 6. Average wholesale electricity price change by state: Hybrid $100 \%$ CES (\$40 ACP) plus tax credit extension (\$/MWh)

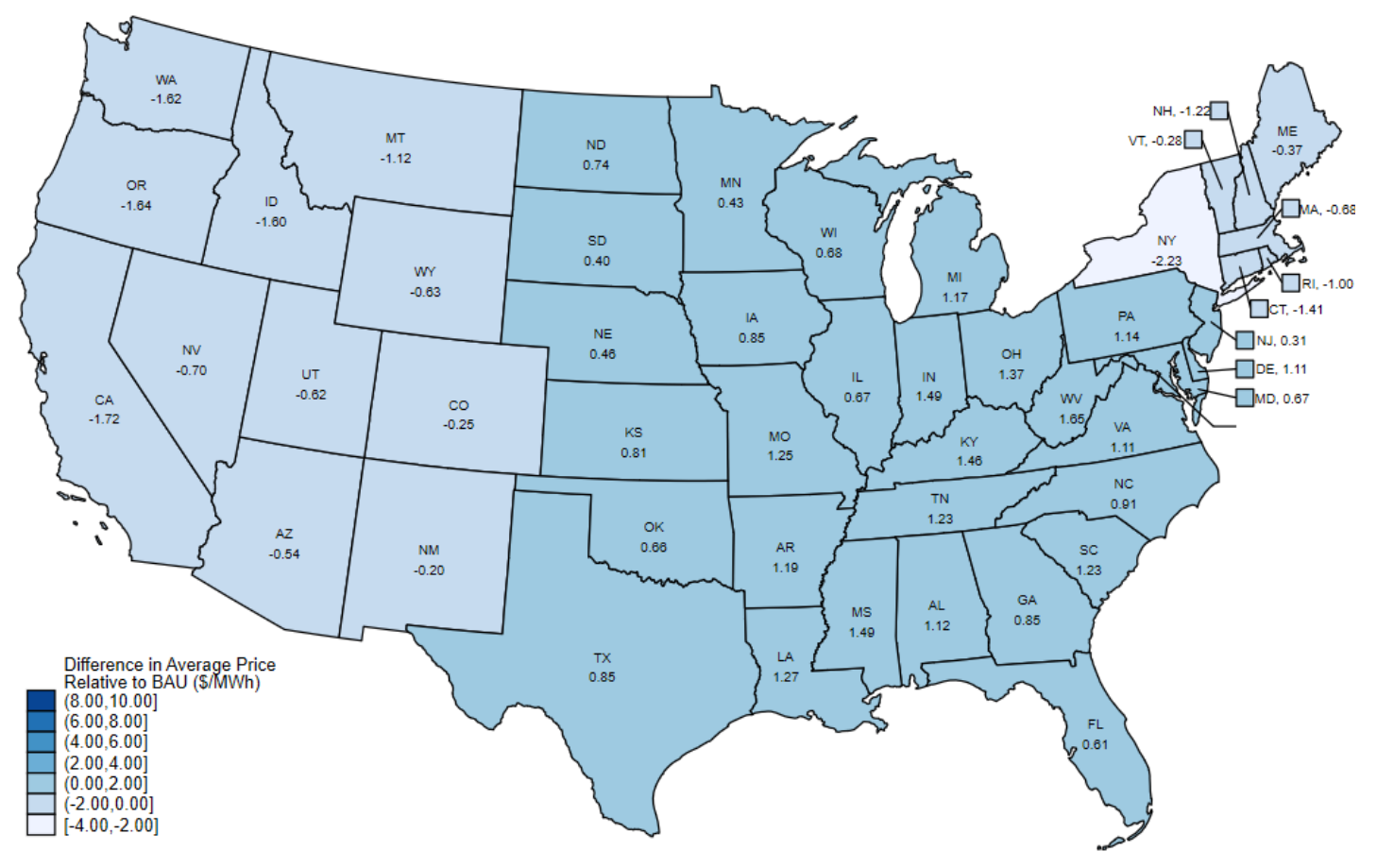


Figure 7. Average wholesale electricity price change by state: 90\% CES (\$/MWh)

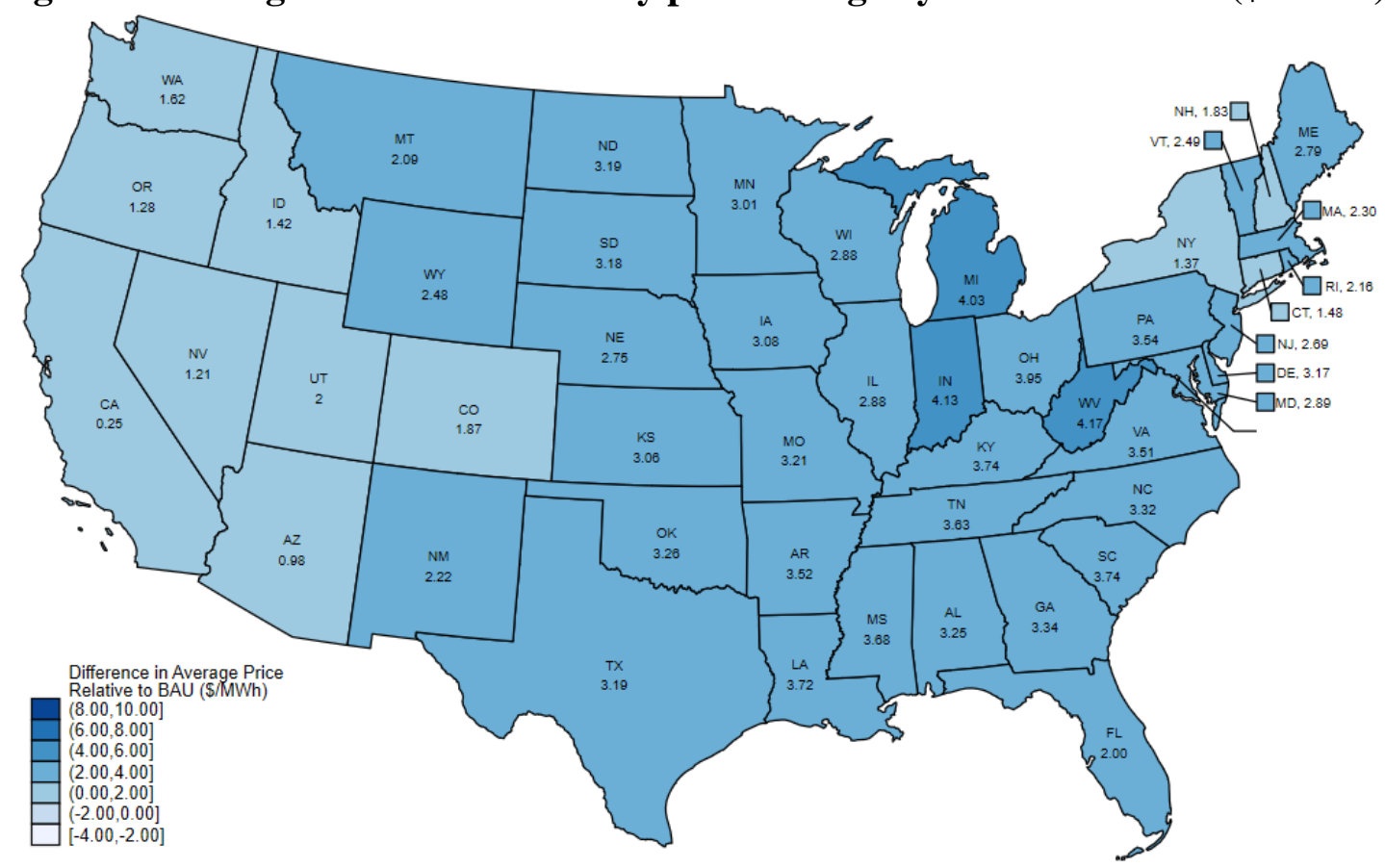

Figure 8. Average wholesale electricity price change by state: $\$ 40$ carbon tax with percapita dividend $(\$ / \mathrm{MWh})$

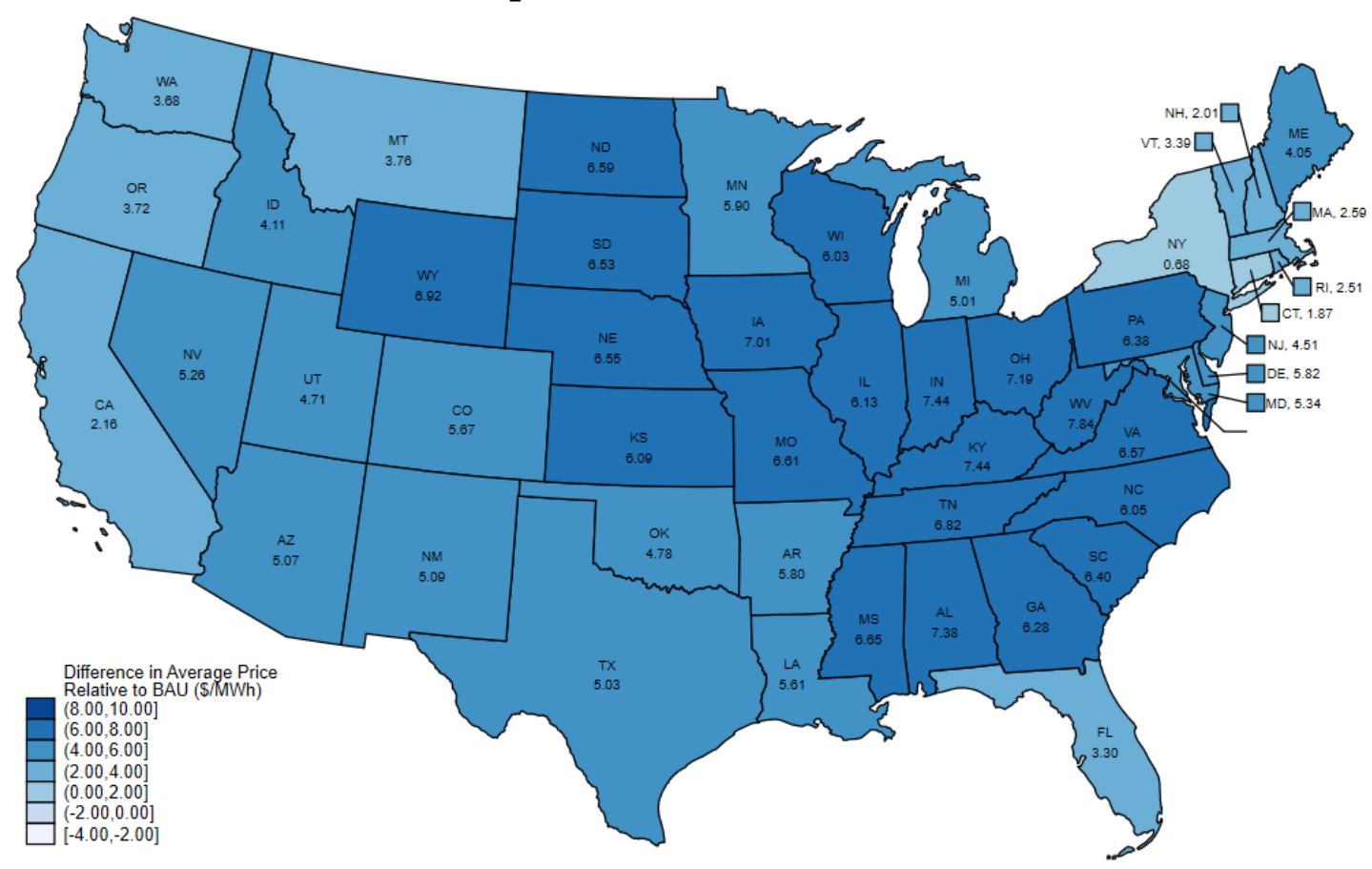




\section{Discussion}

These results have some important caveats. First, we obtained these results using the ReEDS model. That model is widely used in the recent public discussion over power sector decarbonization, e.g. Phadke et al. (2020), and our results align with those for specific cases and policies from EIA AEO (2018, 2020). Still, like all models, ReEDS has limitations and the specific numerical values should be treated circumspectly. Second, the simulations are deterministic and thus abstract from the important problem of price volatility in tradeable allowance systems. Although clean electricity credit prices under the rate-based TPS and hybrid CES would be expected to be less sensitive to demand conditions than under a mass-based system, prices in rate-based permit systems still can fluctuate widely in the presence of technological or policy design constraints that inhibit compliance (e.g., under the Renewable Fuel Standard, see Irwin, McCormack and Stock 2020). Those price fluctuations can retard investment, potentially increasing costs. Third, the deep decarbonization under some of these policies requires more than doubling current rates of construction of wind and solar facilities and installing large quantities of grid storage. ${ }^{21}$ Whether that increased production can in fact happen, especially without new long-distance transmission lines, remains to be seen.

We approached this policy evaluation problem from the perspective of ensuring that the policy achieve a prespecified target - at least $80 \%$ emissions reductions by 2035 - across a range of possible trajectories for total electricity demand, technology prices, and natural gas prices.

Our main finding is that the TPS and hybrid 100\% CES with \$40 ACP lead to 2035 robust decarbonization, but the other policies do not; notably, simply extending the tax credits does not provide an insurance policy for deep decarbonization in the event that an economy-wide carbon tax or sectoral standards are not adopted. From a theoretical perspective, it is perhaps not surprising that the TPS and hybrid CES are successful, because they both are rate-based policies that target $\mathrm{CO}_{2}$ emissions rates either explicitly or in effect. Perhaps more surprising is that they do so quite efficiently (in comparison to the emissions-equivalent first-best policy); that even in the worst case, their cost per ton abated is substantially less than the SCC; and that electricity prices rise only modestly across all scenarios, leading to price increases for the typical household of $-\$ 17$ to $\$ 57$ annually. Those price increases can be reduced or turned into decreases by shifting the costs from the ratepayer to the taxpayer through additionally extending the PTC and ITC, however doing so comes at high fiscal expense.

\footnotetext{
21 The $\$ 40$ carbon tax requires the most new capacity built in the short-run to replace coal generation. New annual capacity of solar, wind and battery storage averages $63.8 \mathrm{GW}$ from 2022-2030 under the reference $\$ 40$ carbon tax scenario. Planned new annual capacity of solar, wind and battery storage was $32 \mathrm{GW}$ in 2021 (https://www.eia.gov/todayinenergy/detail.php?id=46416). Because the other policies ramp in over time, the incremental new capacity is relatively modest. For example, under the reference TPS scenario, new annual capacity of solar, wind and battery storage averages 38.2 GW from 2022-2030.
} 
The main reason that the other policies do not achieve 2035 robust decarbonization is that they target different goals. For example, the $90 \%$ CES achieves $90 \%$ clean electricity, but if gas is expensive, the non-clean $10 \%$ of generation has a high coal share. The PTC/ITC extension does support new renewables construction, but unless gas is expensive, it remains economic to maintain a large share of gas generation, even if renewables comprise most new generation capacity.

Finally, none of these policies achieve the Biden administration's objective of a $100 \%$ clean power sector by 2035 . To obtain deeper decarbonization - or to obtain the levels of decarbonization estimated in this paper, but at a lower cost - requires, among other things, new storage technologies and new interstate transmission capacity. 


\section{References}

Bistline, John, Jared Creason and Brian Murray (Eds.) 2018. "Special section on The EMF 32 study on technology and climate policy strategies for greenhouse gas reductions in the U.S. electric power sector.” Energy Economics 73: Pages 1-426.

Coglianese, John, Todd D. Gerarden, and James H Stock. 2020. "The Effects of Fuel Prices, Regulations, and Other Factors on U.S. Coal Production, 2008-2016." The Energy Journal 41 (1): 55-81.

Fawcett, Allen, Jim McFarland, Adele Morris and John Weyant (Eds.) 2018. "Special Issue on EMF 32 Study on U.S. Carbon Tax Scenarios.” Climate Change Economics 9 (1).

Gillingham, Kenneth and James H. Stock. 2018. "The Cost of Reducing Greenhouse Gas Emissions.” Journal of Economic Perspectives 32(4): 53-72.

Goulder, Lawrence H., and Mark A. C. Hafstead. 2018. Confronting the Climate Challenge: U.S. Policy Options. New York: Columbia University Press.

Goulder, Lawrence H., Marc A. C. Hafstead, and Roberton C. Williams III. 2016. "General Equilibrium Impacts of a Federal Clean Energy Standard." American Economic Journal: Economic Policy, 8 (2): 186-218.

Greenstone, Michael and Ishan Nath. 2020. "Do Renewable Portfolio Standards Deliver CostEffective Carbon Abatement?” Becker-Friedman Institute Working Paper.

Irwin, Scott H., Kristen McCormack, and James H. Stock. 2020. "The Price of Biodiesel RINS and Economic Fundamentals," American Journal of Agricultural Economics 102(3): 734752.

Larsen, John, Noah Kaufman, Peter Marsters, Whitney Herndon, Hannah Kolus, and Ben King. 2020. "Expanding the Reach of a Carbon Tax: Emissions Impacts of Pricing Combined with Additional Climate Actions." Columbia Center for Global Energy Policy.

Larsen, John, Ben King, Hannah Kolus, and Whitney Herndon. 2021. "Pathways to Build Back Better: Investing in 100\% Clean Electricity.” White Paper. Rhodium Group at https://rhg.com/research/build-back-better-clean-electricity/. 
Lawrence Berkeley National Laboratory. 2020. "Wind Technologies Market Report.” Technical Report.https://emp.lbl.gov/sites/default/files/2020_wind_energy_technology_data_update .pdf

Lawrence Berkeley National Laboratory. 2020. ““Utility-Scale Solar Data Update.” Technical Report. https://emp.lbl.gov/sites/default/files/2020_utility-scale_solar_data_update.pdf

National Renewable Energy Laboratory. 2020. “Annual Technology Baseline.” Technical Report. https://atb.nrel.gov/

National Renewable Energy Laboratory. 2021. "Electrification Futures Study: Scenarios of Power System Evolution and Infrastructure Development for the United States." Technical Report. https://www.nrel.gov/docs/fy21osti/72330.pdf

National Renewable Energy Laboratory. 2020. "2020 Standard Scenarios Report: A U.S. Electricity Sector Outlook.” Technical Report. https://www.nrel.gov/docs/fy21osti/77442.pdf

Nemet, Gregory F. 2019. How Solar Energy Became Cheap. New York: Rutledge.

Phadke, Amol et al. 2020. "The 2035 Report: Plummeting Solar, Wind, and Battery Costs Can Accelerate our Clean Electricity Future.” White Paper. Goldman School of Public Policy. 


\section{Appendix}

\section{A.1 Myopic Expectations and Negative Abatement Costs}

Following standard practice with the ReEDS model, the results in this paper assume myopic expectations. That is, investment and generation decisions today are made to minimize system costs assuming today's prices and policies extend into the future. In contrast, many power sector models including EIA NEMS and RFF's E4ST assume perfect foresight, in which today's investment and generation decisions are made to minimize system costs according to a deterministic future sequence of prices and policies. Myopic expectations allow for the possibility of mistakes in that sequential cost-minimization may not yield the same solution as dynamic optimization with perfect foresight.

The use of myopic expectations results in some odd results in Tables 2 and 3 under certain technology cost assumptions, including negative average abatement costs at low levels of abatement and higher system costs under a cap-and-trade than a tradeable performance standard. Appendix Figure 1 demonstrates this issue for the TPS and the emissions-equivalent C\&T under the low renewables and high natural gas technology scenario.

\section{Appendix Figure 1. Annual Generation, TPS Minus Emissions-Equivalent C\&T}

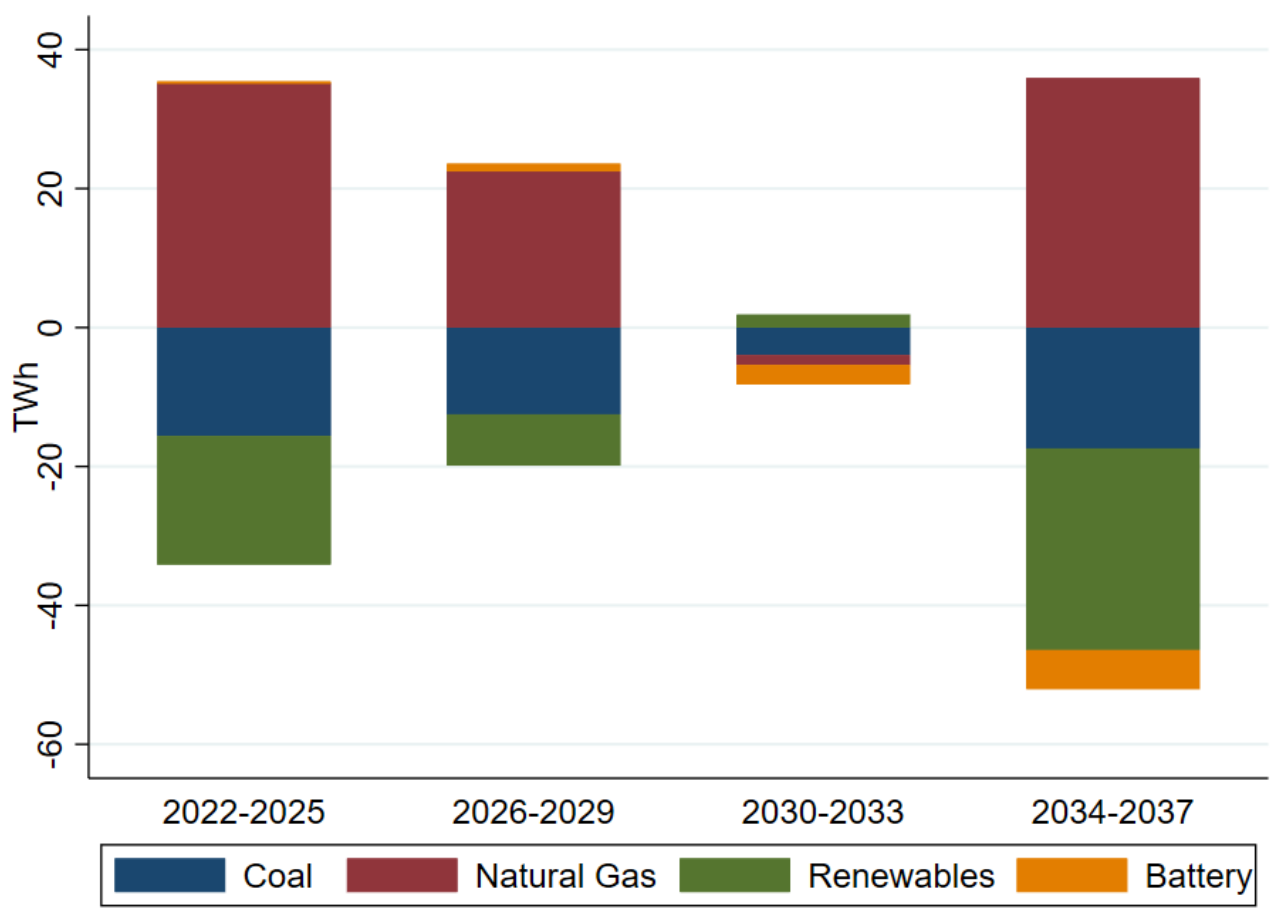

Under the TPS, there is more natural gas generation and less coal/renewable generation than the emissions-equivalent C\&T due to the implicit output subsidy for natural gas generation. 
Appendix Figure 2 demonstrates that system costs are in fact lower under the emissionsequivalent cap-and-trade for the first model period. However, the decision is dynamically inconsistent. The emissions-equivalent C\&T's solution is cheaper before 2030, but more expensive after. Thus, total system costs are actually higher under the emissions-equivalent C\&T.

\section{Appendix Figure 2. Average System Costs, TPS Versus Emissions-Equivalent C\&T}

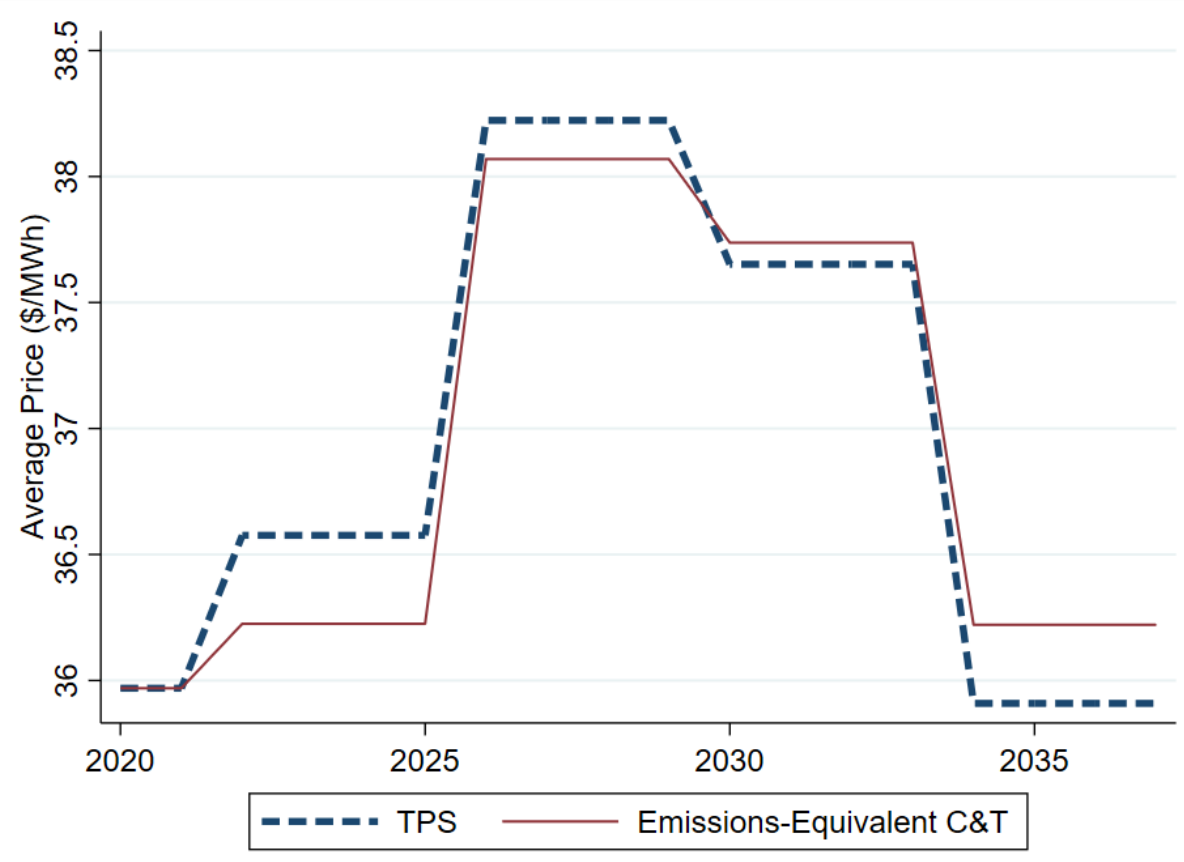

This issue could be mechanically resolved by running the model with perfect foresight and allowing for intertemporal banking and borrowing under the C\&T system.

\section{A.2 Perfect Foresight versus Myopic Expectations}

ReEDS is capable of being solved with perfect foresight. However, there are additional important differences between the perfect foresight and myopic expectations results in the baseline scenario. Appendix Figure 1 depicts baseline carbon emissions under myopic expectations versus perfect foresight. 


\section{Appendix Figure 3. Annual Carbon Emissions, Perfect Foresight Versus Myopic Expectations}

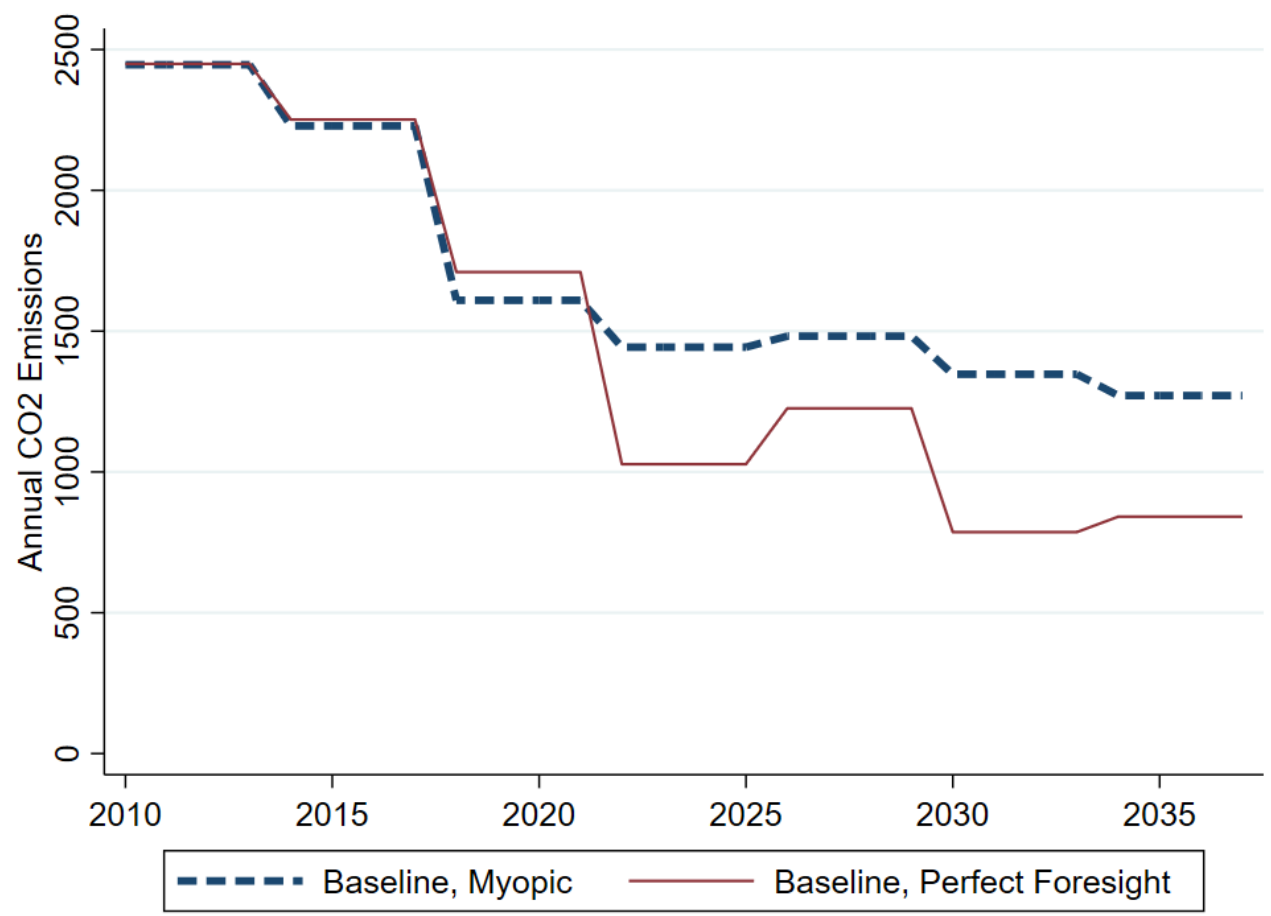

Baseline carbon emissions are 34\% lower in 2035 under the perfect foresight model solution than myopic expectations. Under perfect foresight, the model recognizes the declining costs of solar, the phase-out of the production tax credit for wind (which it takes to be permanent), and the role of natural gas capacity as a least-cost source of peak generation under high renewable penetration. As a result, $128 \mathrm{GW}$ of wind and $50 \mathrm{GW}$ of natural gas are built out from 20222026, $300 \mathrm{GW}$ of solar are built out from 2030-2034, and 7GW of battery capacity are built out from 2034-2038. Due to this capacity expansion, over 50\% of coal generation is displaced between 2022-2026, leading to a short-term decline in carbon emissions.

To ensure our results are comparable with EIA's AEO and to align with standard practice using ReEDS (e.g., NREL Standard Scenario Report, 2020; Phadke et al. 2020), we present results using myopic expectations. However, to explore the robustness of our conclusions, Appendix Table 1 compares outcomes for six climate policies under reference cost and electrification assumptions. The most important difference between myopic expectations and perfect foresight is the baseline level of carbon emissions in 2035. Because the baseline is so much lower under perfect foresight (and much lower than EIA AEO $(2020,2021)$ ) and marginal abatement costs are convex in the level of abatement, average abatement costs are 32-345\% higher under perfect foresight than myopic expectations. 
However, the carbon tax, TPS and 90\% CES still achieve deeper decarbonization than the PTC/ITC extension or state CES policies. Additionally, the PTC/ITC extension is much less cost-effective with perfect foresight. This is because the model anticipates the phase-out of the production tax credit for wind, bringing forward investment in new wind capacity. Thus, an extension of the PTC/ITC tends to only alter the timing of inframarginal wind investment, inducing little additional investment.

\section{Appendix Table 1. Carbon Emissions and Average Abatement By Climate Policy, Myopic Expectations versus Perfect Foresight}

\begin{tabular}{lcccc}
\hline Climate Policy & $\begin{array}{c}\text { Annual CO2 } \\
\text { Emissions in 2035 }\end{array}$ & $\begin{array}{c}\text { 2035 Emissions } \\
\text { as fraction of } \\
\text { 2005 Emissions }\end{array}$ & $\begin{array}{c}\text { Cumulative } \\
\text { Abatement }\end{array}$ & $\begin{array}{c}\text { Average } \\
\text { Abatement Cost }\end{array}$ \\
\hline Myopic Expectations & & & & \\
BAU & 1,349 & 0.558 & - & - \\
\$40 Carbon Tax & 231 & 0.096 & 17,050 & $\$ 29.0$ \\
TPS & 309 & 0.128 & 10,612 & $\$ 25.5$ \\
90\% CES & 267 & 0.111 & 7,518 & $\$ 32.5$ \\
PTC/ITC Extension & 906 & 0.375 & 3,494 & $\$ 50.5$ \\
State CES & 1,302 & 0.539 & -389 & - \\
Perfect Foresight & & & & \\
BAU & 841 & 0.348 & - & - \\
\$40 Carbon Tax & 78 & 0.032 & 12,673 & $\$ 47.9$ \\
TPS & 284 & 0.118 & 6,501 & $\$ 34.8$ \\
90\% CES & 257 & 0.106 & 5,524 & $\$ 42.9$ \\
PTC/ITC Extension & 472 & 0.195 & 1,006 & $\$ 174.2$ \\
State CES & 829 & 0.343 & 147 & $\$ 27.8$ \\
\hline
\end{tabular}

